Phenomenological Models for Landscape Signatures: Review and Recommendations

Jerrell R. Ballard, Jr., George L. Mason, James A. Smith, and Lee K. Balick
March 2004

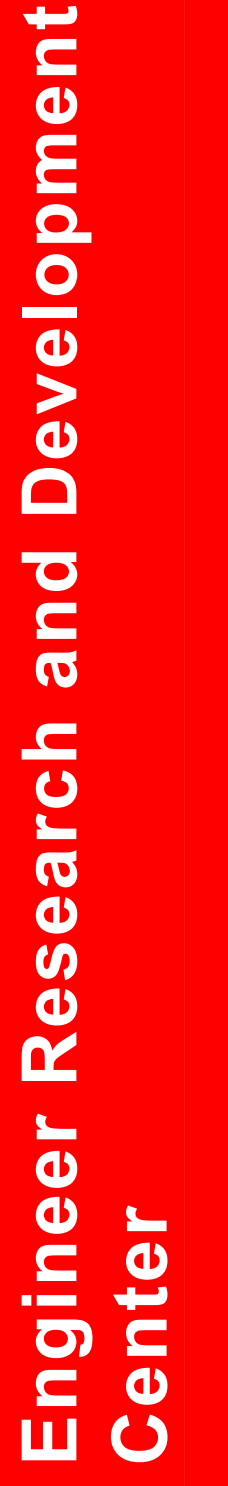


ERDC TR-04-2

March 2004

\title{
Phenomenological Models for Landscape Signatures: Review and Recommendations
}

\author{
Jerrell R. Ballard, Jr. \\ Environmental Laboratory \\ U.S. Army Engineer Research and Development Center \\ 3909 Halls Ferry Road \\ Vicksburg, MS 39180-6199 \\ George L. Mason \\ Geotechnical and Structures Laboratory \\ U.S. Army Engineer Research and Development Center \\ 3909 Halls Ferry Road \\ Vicksburg, MS 39180-6199 \\ James A. Smith \\ Laboratory for Terrestrial Physics \\ Code 920 \\ NASA Goddard Space Flight Center \\ Greenbelt, MD 20771 \\ Lee K. Balick \\ Space and Remote Sensing Sciences Group (NIS-2) \\ Los Alamos National Laboratory \\ P.O. Box 1663 \\ Los Alamos, NM 87545
}

Final report

Approved for public release; distribution is unlimited

Prepared for U.S. Study Program Management Office - G8

1725 Jeffson Davis Highway, Crystal Square 2, Suite 201A

Arlington, VA 22202 


\begin{abstract}
This report reviews, evaluates, and recommends atmospheric, environmental, and geophysical models that use physics to aid in understanding the impact that the natural environment has on the sensors that are commonly applied to the mine detection problem (either surface or buried). The report lists important predictive high-resolution atmospheric, environmental, and geophysical models. Priority models are evaluated to indicate their strengths and weaknesses. The report recommends areas needing further development to fill the gaps in predicting the effects of critical environmental factors on developing mine detection sensors.
\end{abstract}

DISCLAIMER: The contents of this report are not to be used for advertising, publication, or promotional purposes. Citation of trade names does not constitute an official endorsement or approval of the use of such commercial products. All product names and trademarks cited are the property of their respective owners. The findings of this report are not to be construed as an official Department of the Army position unless so designated by other authorized documents. 


\section{Contents}

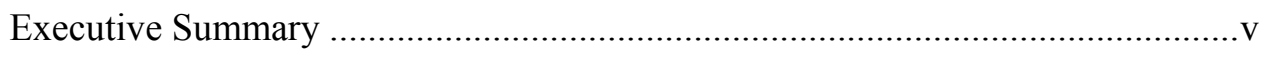

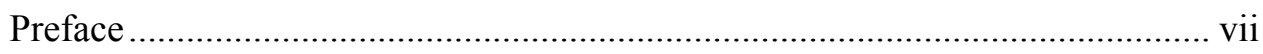

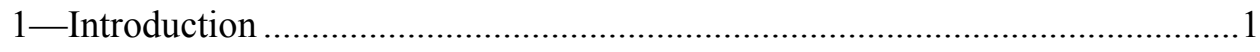

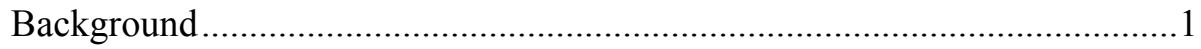

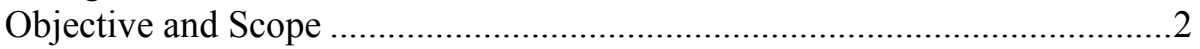

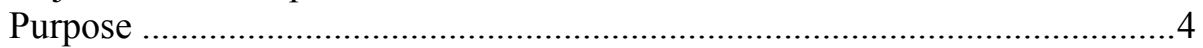

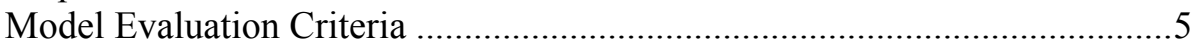

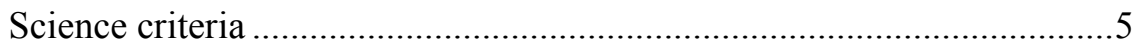

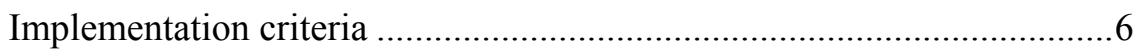

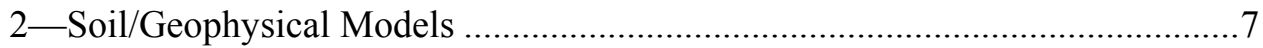

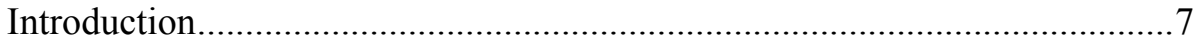

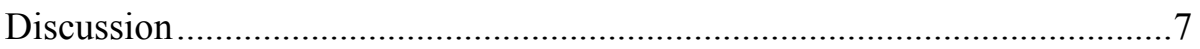

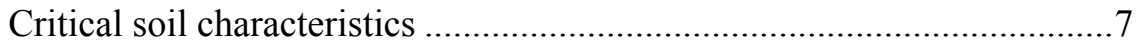

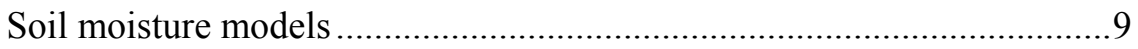

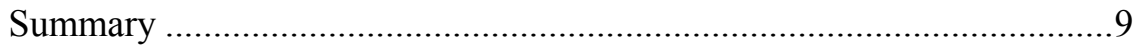

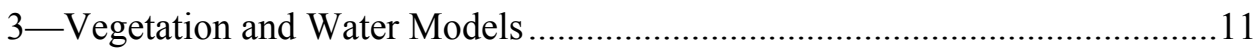

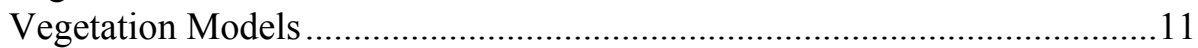

Vegetation reflectance models .............................................................11

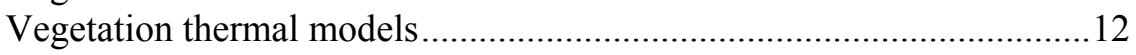

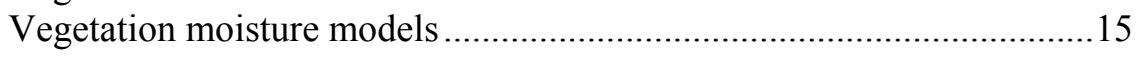

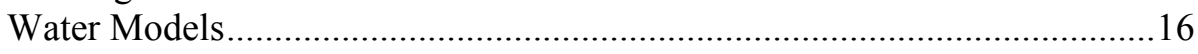

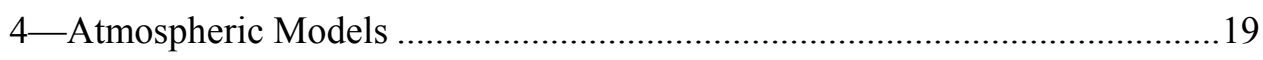

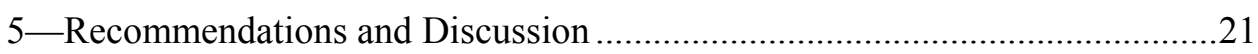

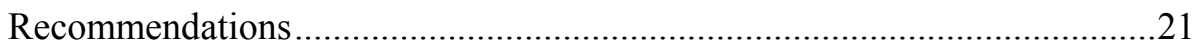

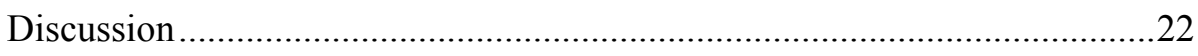

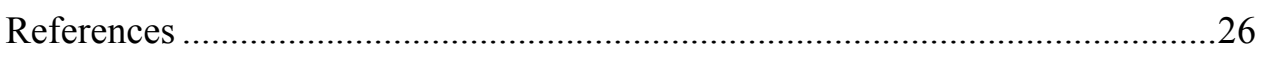

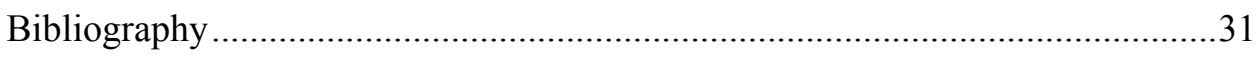

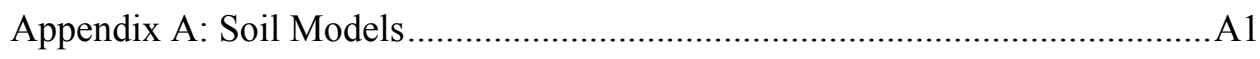

Appendix B: Vegetation and Water Models ..................................................... B1

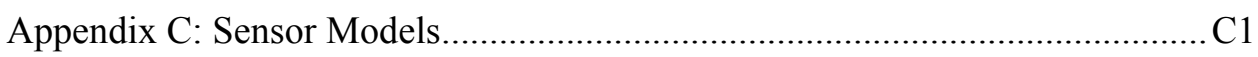

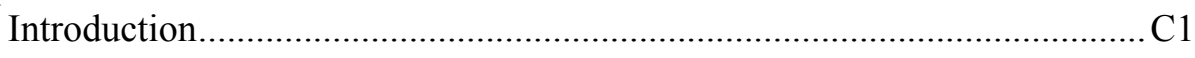

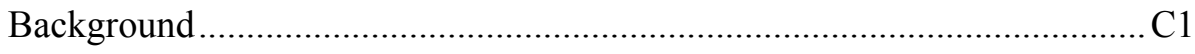

SF 298 


\section{List of Figures}

Figure 1. Environmental factors affecting mine signatures .......................5

Figure 2. Moisture/temperature models .................................................9

Figure 3. Energy balance of a single leaf............................................. 13

Figure 4. Estimated temperature differences in a healthy vegetated (grass) background .................................................................13

Figure 5. Observed temperature differences between two grass thermal images collected $20 \mathrm{sec}$ apart .......................................14

Figure 6. Wet soil and surface water conditions during a field test...........17

Figure 7. Overhead image of road with standing water...........................17

\section{List of Tables}

Table 1. Relevant Army Science and Technology Objectives ...................3

Table 2. Sensing Technologies and Important Soil Properties....................8

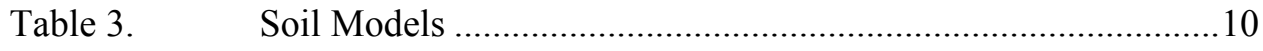

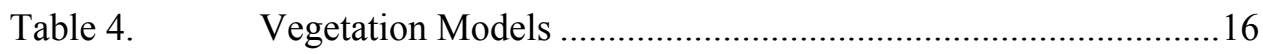

Table 5. General State Parameters Used in Atmospheric Models............19

Table 6. Reviewed Atmospheric Models .................................................20

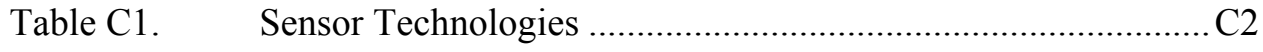

Table C2. Summary of Sensor Models ................................................... 3 


\section{Executive Summary}

The overall purpose of this report is to review, evaluate, and recommend atmospheric, vegetation and water, and soil models that provide a physics-based understanding of the natural environment and its impact on sensors most commonly applied to the mine (surface or buried) sensing problem. Specific objectives of this report are as follows:

a. List important predictive high-resolution atmospheric, vegetation and water, and soil models.

b. Evaluate priority models to indicate strength and weakness of the models.

c. Recommend areas that require development to fill the gaps in predicting effects of critical environmental factors on developing mine detection sensors.

Specifically, the models recommended in this report are applicable to conceptual wavelengths of airborne mine detection sensors in development at the U.S. Army Night Vision and Electronic Sensors Directorate (NVESD). Many models are available to predict temperature and moisture profiles in soils, vegetation, and atmosphere but questions of scale (time and space) and dimensionality (1D-3D) are of some importance.

For a physics-based understanding of the natural environment and its impact on sensors, the following recommendations are made:

a. Soil. The simulation of the transient or steady-state density dependent flow field described by the 3-Dimensional Subsurface Flow and Fate and Transport of Microbes and Chemicals (3DFATMIC) model (Yeh et al. 1997) and other similar models.

b. Vegetation.

(1) Reflectance. Spectral models from Kimes and Kirchner (1982), Verhoef (1984), and Verhoef and Bach (2003).

(2) Thermal. For large area short canopies, Balick et al. (1981b); for complex vegetation canopies, Smith et al. (1981); for large individual trees, Hummel et al. (1991); and for small plants/shrubs, Dauzat et al. (2001). 
(3) Moisture. Algorithms for water flow model for trees (Edwards et al. 1986) or water balance for forests (Granier 1994).

c. Water. Algorithms from the CE-QUAL-W2 (Wells and Cole 2000).

d. Atmospheric. The moderate resolution transmittance (MODTRAN4) model for atmospheric transmittance and emittance (Air Force Research Laboratory 2003). 


\section{Preface}

This report reviews phenomenological models to increase understanding of the natural environment and the impact of the environment on airborne sensors most commonly applied to mine (surface or buried) detection. The study was performed with funds provided by the U.S. Army Study Program Management Office. The aim of this study was to provide guidance and information for U.S. Army modeling and analysis efforts to improve mine detection in support of the investigation, "Impact of Complex Environmental Features on Mine Detection," Mr. Jerrell R. Ballard, Jr., U.S. Army Engineer Research and Development Center (ERDC), principal investigator.

This report was prepared by Mr. Jerrell R. Ballard, Jr. Environmental Systems Branch (ESB), Ecosystem Evaluation and Engineering Division (EEED), Environmental Laboratory (EL), U.S. Army ERDC; Dr. George L. Mason, Mobility Systems Branch, Engineering Materials and Science Division, Geotechnical and Structures Laboratory, U.S. Army ERDC; Dr. Lee K. Balick, Space and Remote Sensing Sciences Group, Los Alamos National Laboratory; and Dr. James A. Smith, Laboratory for Terrestrial Physics, Code 920, NASA Goddard Space Flight Center.

This report was prepared under the general supervision of Dr. M. Rose Kress, Chief, ESB; Dr. David J. Tazik, Chief, EEED; and Dr. Beth Fleming, Acting Director, EL.

At the time of publication of this report, Dr. James R. Houston was Director of ERDC, and COL James R. Rowan, EN, was Commander. 


\section{Introduction}

\section{Background}

Mine detection remains a critical problem, and its importance will significantly increase as the Army transitions to a lighter, more mobile Future Force or, as in recent years, participates for sustained periods in multi-national efforts in countries such as Afghanistan, Kosovo, and Iraq where local area support is required. There are over 2,500 types of mines in the world consisting of both metallic and non-metallic materials in various shapes and with varying explosive charges and mechanisms (Kendall 2001).

Mine detection remains one of the most vexing problems facing the military. Detecting these small objects in large areas is especially difficult where the character of the large areas is highly heterogeneous with features that can mask the presence of the mine. It is this complex and dynamic environment that presents both the problem and the opportunity to more effectively detect minefields and mines. Rapid evaluation, improvement, and fielding of advanced mine sensing technologies will enhance the capability of the Object Force for mobility across the operational spectrum. The Army has capabilities to characterize, model, and analyze complex terrain and to integrate that knowledge into the sensing environment that can provide a new dimension for mine detection technology development. A significant enabler in applying this approach is the evolution of physics-based models that allow signature prediction of many terrain features and conditions to electromagnetic, electro-optical, and chemical sensors. These models have been a principal thrust in the Army Corps of Engineers Labs for many years and have focused on sensing technologies that are directly applicable to the problem of sensing buried mines (for example, thermal IR and multispectral imaging, and ground-penetrating and millimeter wave radars). In addition, numerous analytical and numerical models that predict the physical properties of the shallow subsurface have been developed in a variety of programs. The fundamental knowledge of the character of the terrain (e.g. topography, vegetation types, soil types, and electromagnetic properties of the shallow subsurface) and the accompanying dynamic processes that alter the properties of the terrain (predominantly season, time-of-day, and weather) are key to these models. These models allow a significant advantage in not having to consider the natural environment as statistical clutter. Instead, the specific geometric and material properties of the terrain can be considered and exploited. This study focused on those relevant models that provide a physics-based understanding of the environment and its impact on the EO sensor most 
commonly applied to the mine detection problem. Time did not allow for evaluation of models for other sensing concepts (SAR, EM, etc.).

Much of the electromagnetic spectrum, active and passive, has been exploited in countermine technology. Detection methods use either direct sensing of mine material properties or morphology or indirect sensing of the modified background arising from mine emplacement or disturbance, e.g. voids, surface roughening, modification of moisture and temperature regimes. Optimum spatial and temporal sampling has been studied as a function of sensor type and wavelength regime (Witten 1998, Carin 2001, Harmon et al. 2003). The deleterious impacts of varying environmental conditions even on simple mine detection technology have long been recognized. Such effects may become even more of a factor with increasing sophistication in employing multiple sensors exploiting the full suite of spatio-temporal target/background variations (Van Dam et al. 2003).

All current mine detection technologies require that the distribution and variability (in time and space) of the key environmental variables of solar insulation, precipitation, wind speed, and local or regional profiles of soil or vegetation moisture and temperature be understood. If these factors and the ability to model them in a variety of multidimensional domains become well defined, then sensor and algorithm simulation test beds can more realistically be tailored to particular operational scenarios and technologies.

Significant success has been achieved but some general themes are emerging. Given the widely different roles in which mine detection systems will be used and the tremendous variability in environmental conditions for their use, it is highly unlikely that any one sensing system will provide adequate detection performance. Rather, sensor multiple systems, possibly employing data fusion or other more sophisticated processing algorithms, will be required (MacDonald et al. 2003).

Several types of model reviews have been conducted for landscape and atmospheric studies. A report (Balick et al. 1990) was commissioned by the Balanced Technology Initiative (BTI) Smart Weapons Operability Enhancement (SWOE) Program Management Office to provide an independent review of physics-based models suitable for estimating surface temperatures of thermal infrared natural background components for thermal image generation. Later a survey of environmental and atmospheric models was conducted by the Air Force (Burgeson et al. 1996) sponsored by the Defense Modeling and Simulation Office to identify models containing physics-based environmental effects for modeling and simulation applications. These reviews were used as a starting point for this study.

\section{Objective and Scope}

The objective of this study is to inventory, evaluate, and document relevant analytical and numerical vegetation and water and soil models in order to predict 
the impact of key physical variables and features on the performances of developing mine detection sensors.

Current and emerging 1D, 2D, and 3D analytical and numerical vegetation and water and soil models will be inventoried and evaluated in order to determine their ability to predict and provide information for improved understanding of performances of candidate mine detection sensors. The study will include physics-based models developed by U.S. Army Labs and other university efforts. These models must be directly applicable to predicting variability of critical environmental factors, such as soil moisture, based on dynamic weather conditions and also must predict for high-resolution landscape scales.

The study will provide critical evaluations of the most promising analytical and numerical models that can be used to predict the impact of the environment on mine-sensing technologies. The resulting suite of models will then be used in a follow-on funded mine detection program to demonstrate how increased knowledge of the environment can be used to conduct trade-off evaluations of candidate mine sensing technologies.

This study has focused on landscape and atmospheric physics-based models relevant to EO/IR sensor concepts. These predictive models will be used in the proposed joint U.S. Army Engineer Research and Development Center (ERDC)/U.S. Army Night Vision and Electronic Sensors Directorate (NVESD) Innovative Countermine Phenomenology Initiative. The ERDC's primary focus will be on applying geo-environmental models and characterization methods for predicting and defining the variability of test environments, considered representative of the operational environments. Candidate models considered in this study are models that provide a physics-based understanding of the natural environment and its impact on sensors most commonly applied to the mine (surface or buried) detection problem. The focus of this study is also limited to EO/IR models that are directly applicable to the emerging Army candidate mine detection sensor concepts and Army Science and Technology Objectives (STO) listed in Table 1 below.

\begin{tabular}{|l|l||}
\hline \multicolumn{2}{||l||}{$\begin{array}{l}\text { Table } 1 \\
\text { Relevant Army Science and Technology Objectives }\end{array}$} \\
\hline \hline Name & Technology \\
\hline \hline Light-weight Airborne Multispectral Mine Detection & Spectral and thermal sensors \\
\hline Wide Area Airborne Detection & Spectral and thermal sensors \\
\hline $\begin{array}{l}\text { Overhead Sensor Technology for Battlefield } \\
\text { Characterization }\end{array}$ & Hyperspectral and thermal sensors \\
\hline $\begin{array}{l}\text { Future Combat System Mine Detection and } \\
\text { Neutralization }\end{array}$ & Spectral and thermal sensors \\
\hline Countermine Phenomenology Studies & $\begin{array}{l}\text { Spectral, thermal, radar, and laser } \\
\text { sensors }\end{array}$ \\
\hline
\end{tabular}

Most of the STO's are focused on the spectral and thermal sensing (also referred to as EO/IR) concepts. Significant research is being conducted on other sensing concepts, namely seismic, acoustic, ground-penetrating radar, synthetic 
aperture radar, chemical detection, and electromagnetic mine detection, but these concepts were not addressed due to time and funding constraints.

\section{Purpose}

The overall purpose of this report is to review, evaluate, and recommend atmospheric, vegetation and water, and soil models that provide a physics-based understanding of the natural environment and the impact of that environment on airborne EO/IR sensors most commonly applied to the mine (surface or buried) detection problem. The specific objectives of this report are to:

a. List important predictive high-resolution atmospheric, vegetation and water, and soil models.

b. Evaluate priority models to indicate strength and weakness of the models.

c. Recommend areas that require development to fill the gaps in predicting effects of critical environmental factors on developing mine detection sensors.

Specifically, the models recommended in this report are ones that are applicable to conceptual wavelengths of airborne mine detection sensors under development by NVESD. Many models are available to predict temperature and moisture profiles in soils, vegetation, and atmosphere but questions of scale (time and space) and dimensionality (1D-3D) must be considered.

This report is organized into three main parts, soil (geophysical), vegetation and water (environmental), and atmospheric models. Appendices A through C contain detailed descriptions of the models reviewed. Soil (geophysical) models are models that describe the physical processes and phenomena occurring within the earth and vicinity. Vegetation and water (environmental) models are models that describe the physical and radiative processes that are occurring in the biophysical layer of the earth. Atmospheric models are models that describe the physical and radiative processes that are occurring in the near surface atmosphere. Clearly, this categorical separation is only for the organization of the review and description purposes, since none of these processes is isolated from the others and in the modeling these boundaries are not well defined. These processes in relation to the environment around the mine are illustrated in Figure 1. 


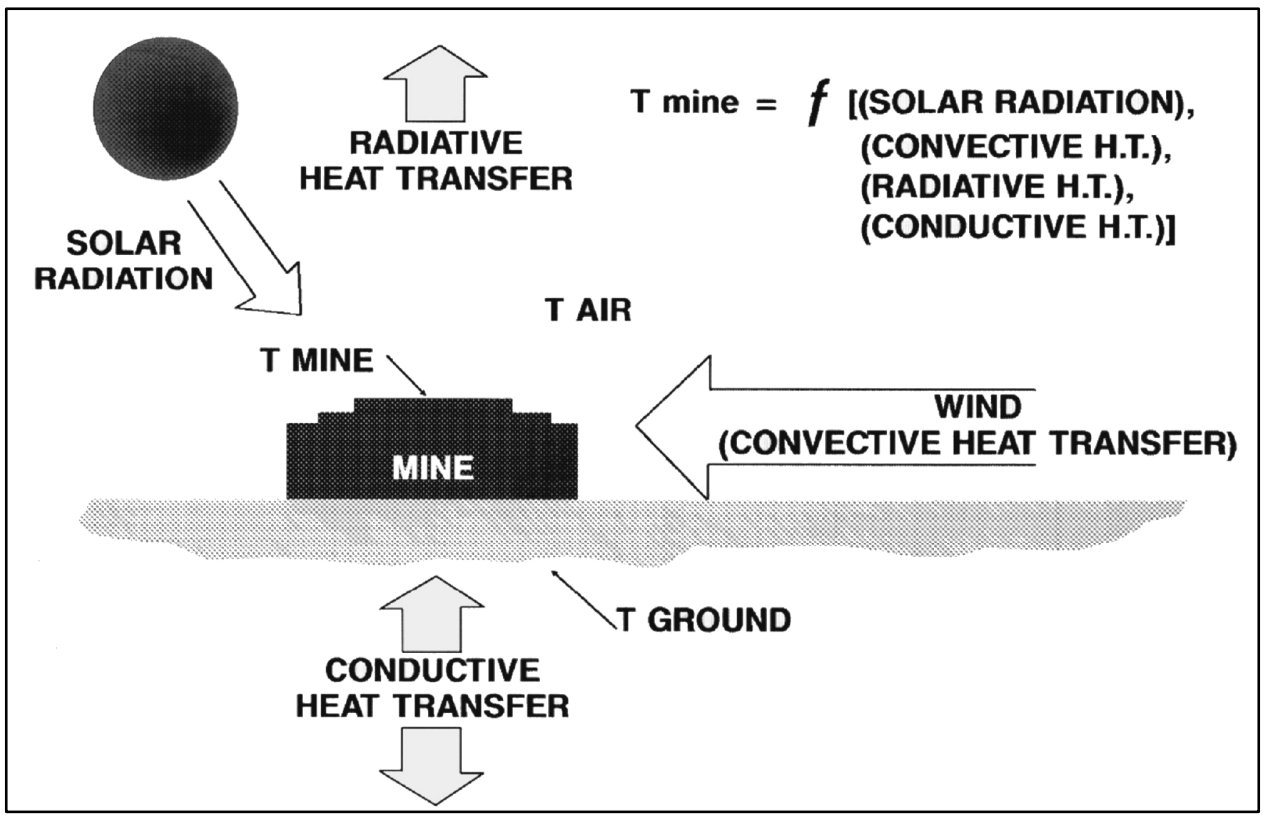

Figure 1. Environmental factors affecting mine signatures

\section{Model Evaluation Criteria}

Models were separated into categories based on the type of environment the model simulated.

\section{Science criteria}

The scientific evaluation criteria used in this model review are based on information previously provided by Balick et al. (1990) in a review of onedimensional temperature models. Their scientific review critera were modified to more general terms and the resulting scientific evaluation of the models was based on the following questions:

a. For what material does the model simulate temperatures, moisture, reflectance, and emittance?

$b$. To what degree does the model rely on fundamental (rather than empirical or parametric) representation of processes?

c. Are the physical processes and environmental factors correct for the simulated material?

d. Are validation and sensitivity of the model established?

$e$. Are the input requirements and expertise required consistent with the Army's operational environment?

$f$. What is the dimensionality of the model?

g. Are there gaps or shortcomings in the modeling procedure? 
Detailed evaluation addressed the appropriateness, completeness, advantages, and unique features of techniques used in the models. Techniques examined included those used to evaluate the individual energy budget terms, the numerical methods employed, and requirements for initializing the model. Although the comparison was performed model by model, the best techniques available were sought for each task.

\section{Implementation criteria}

Even though a model may present the best level of scientific content, the model may not be suitable for integration with other models. The model must also be readily available for use in the timeframe of the Army's Innovative Countermine Phenomenology Initiative and be adaptable to the planned software structure presented by the researchers in the program. 


\section{Soil/Geophysical Models}

\section{Introduction}

This section defines soil/geophysical models as they apply to understanding the geophysical (physical, chemical, and biological) processes of the natural environment. The study focuses on the emerging and mature models as they apply to thermal, radar, and acoustic sensing technologies. The models were not run in-house, but were evaluated by the theory by which they were constructed. The authors seek to identify those suited for simulations that can support mine sensing technologies. Deficiencies in the models that would impair the implementation of the simulation are also defined.

Several federal, state, and private agencies have developed soil models. Interest in global climatic warming, crop production, leaching of chemicals in the soil, and prediction of weather have resulted in a great number of soil models. Agencies who have developed these models include the United States Department of Agriculture (USDA), the United States Geological Service (USGS), the United Nations (UN), and the Department of Defense (DoD). The soil models require different levels of input to operate depending on the temporal and spatial scale. Also, if the soil model is developed in conjunction with a satellite system, reflective information may complement some ground truth data.

\section{Discussion}

\section{Critical soil characteristics}

The migration of water through a soil affects the electrical, physical, electromagnetic, and acoustic properties of the soil. When a foreign object is introduced to the soil, the path of the object is influenced. The change in density, moisture, or texture of the soil over the mine provides a signature that changes with time. Kerner et al. (1998) conducted a study regarding the detection of antipersonnel landmines and found that important sensor technologies for good to marginal success include ultra-wideband (UWB) radar systems, hyperspectral, infrared imagery, multispectral video imagery, electromagnetic induction, resistivity, seismometers, gravimetric sensors, lidar, and non-invasive proximate or contacting sensors. Das et al. (2002) suggest that a soil properties database be used to support ongoing countermine studies and provide Table 2 as a starting point for relevant countermine soil properties. Many of the soil properties listed 
are highly correlated to soil moisture, temperature, void ratio, mineral content, and gradation. Characterization of the spatial and temporal variations in the properties of the soil are important for sensor signature predictions.

\begin{tabular}{|c|c|}
\hline \multicolumn{2}{|c|}{$\begin{array}{l}\text { Table } 2 \\
\text { Sensing Technologies and Important Soil Properties (Das et al. } \\
\text { 2002) }\end{array}$} \\
\hline Detection Technology & Main Relevant Soil Properties \\
\hline Magnetostatics & Magnetic susceptibility \\
\hline $\begin{array}{l}\text { Electrical impedance } \\
\text { tomography }\end{array}$ & Electrical conductivity \\
\hline Electromagnetic induction & $\begin{array}{l}\text { Magnetic susceptibility } \\
\text { Electrical conductivity }\end{array}$ \\
\hline Nuclear quadrupole resonance & $\begin{array}{l}\text { Magnetic susceptibility } \\
\text { Electrical conductivity } \\
\text { Electrical permittivity } \\
\text { Piezoelectric materials (e.g. quartz content) } \\
\text { Magnetostrictive materials }\end{array}$ \\
\hline Active and passive microwaves & $\begin{array}{l}\text { Electrical permittivity } \\
\text { Electrical conductivity } \\
\text { Piezoelectric materials (e.g. quartz content) } \\
\text { Magnetostrictive materials }\end{array}$ \\
\hline Infrared & $\begin{array}{l}\text { Thermal resistivity } \\
\text { Thermal diffusivity } \\
\text { Specific heat capacity }\end{array}$ \\
\hline Thermal neutron activation & $\begin{array}{l}\text { Content of elements such as } \\
\mathrm{Fe}, \mathrm{Ti}, \mathrm{Cd}, \mathrm{B}, \mathrm{Gd}, \mathrm{Si}, \mathrm{O}, \mathrm{C}, \mathrm{N}, \mathrm{H}\end{array}$ \\
\hline X-ray backscatter & $\begin{array}{l}\text { Effective density } \\
\text { Effective atomic number and weight }\end{array}$ \\
\hline Neutron moderation & Content of $\mathrm{H}$ \\
\hline Trace explosives detection & $\begin{array}{l}\text { Porosity and moisture content } \\
\text { Cation exchange capacity } \\
\text { Other chemicals and parameters affecting absorption of } \\
\text { explosives }\end{array}$ \\
\hline Acoustic/seismic techniques & Density and bulk modulus \\
\hline Prodders & $\begin{array}{l}\text { Hardness } \\
\text { Acoustic and electromagnetic properties }\end{array}$ \\
\hline
\end{tabular}

Many soil models have been developed over several years. This development has characterized the soil as a layered system, modeling the moisture flow and/or temperature fluxes through the layers (Figure 2). Figure 2 depicts water and heat flow through soil subsurface layers. At any certain depth the water table or flow off an impermeable structure will negate flow out of the final layer of soil. These models are built around field testing that supports relationships among permeability, soil tension, and moisture content of the soil. The boundary conditions of the moisture content of the soil exist between saturation (the point at which all voids are filled with water) and a residual or wilting point of the soil. The permeability of the soil is highest at saturation, while the tension is highest at the wilting point. Potential soil models that are identified by this review tend to be described in two categories, thermal and moisture (Figure 2). 


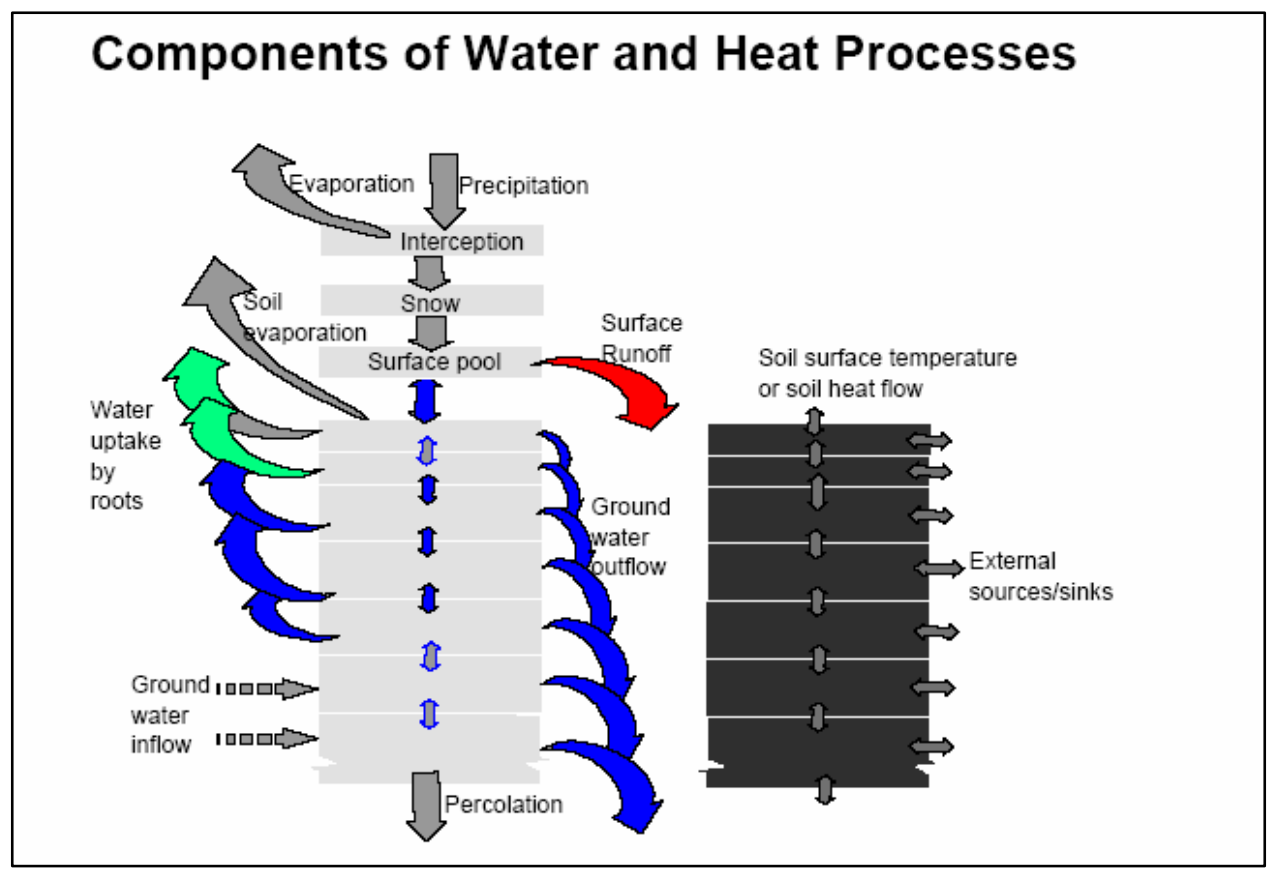

Figure 2. Moisture/temperature models (per Erik Jannsson 2002)

\section{Soil moisture models}

Moisture content is the prime dynamic soil property affecting sensor signatures. A brief literature search was conducted (Table 3 ) to identify soil models that would potentially discriminate between false positives. Details of these models are provided in Apppendix A. The models were characterized as chemical, physical, vegetation/soil, and snow/freeze. Many of these models combined analytical methods and algorithms. The models represent highresolution finite element models supporting multidimensional analysis through simple models such as SoilFug that have only a few soil inputs and generalized soil infiltration equations. Soil moisture and the dielectric properties of soils are considered highly correlated. Soil moisture probes measure the dielectric properties of soil that are correlated to volumetric moisture. There were no models that were based on dielectric concepts; however, there is some recent work by Boyarskii et al. (2002) on dielectric concepts.

\section{Summary}

Several existing soil models support studies of the geophysical environment and its impact on airborne sensor commonly applied to the mine detection problem. The class of problems revolving around minefield detection is multidimensional based on the width, depth, and height of the mine along with materiel composition. Compounding this problem with requirements of a validated soils model, the study suggests that a robust model is required. Of the models considered, the finite element model 3DFATMIC (Yeh et al. 1997) or similar models would support spectral and thermal signature predictions. Extensions of the 3DFATMIC model would be required to include dielectric 
properties of the soil. In addition to these models, surface roughness measures and delineation need to be addressed.

\begin{tabular}{|c|c|c|c|c|c|}
\hline \multicolumn{6}{|l|}{$\begin{array}{l}\text { Table } 3 \\
\text { Soil Models }\end{array}$} \\
\hline Model & Dimensions $^{1}$ & Type & Language & Type & Release \\
\hline SOFT & $1 \mathrm{D}$ & Water & Fortran 77 & Finite Diff & Open \\
\hline FASSST-C & $1 \mathrm{D}$ & Water/Temp & Fortran 77 & Finite Diff & Open \\
\hline ESTAR & $1 \mathrm{D}$ & Water & Fortran & Finite Diff & Open \\
\hline BATS & $1 \mathrm{D}$ & Water/Temp & Fortran & Finite Diff & Open \\
\hline GENESIS & $1 \mathrm{D}$ & Water/Temp & & Finite Diff & Open \\
\hline SoilFug & $1 \mathrm{D}$ & Chemical & Basic & $\begin{array}{l}\text { Closed } \\
\text { Form }\end{array}$ & Open \\
\hline Cemos & $2 \mathrm{D}$ & Chemical & Pascal 7.0 & $\begin{array}{l}\text { Closed } \\
\text { Form }\end{array}$ & Open \\
\hline SESOIL & $1 \mathrm{D}$ & Water/Sediment/Chemical & & Finite Diff & Proprietary \\
\hline HYDROGEOCHEM & 1D & Water/Chemical & Fortran & Finite Diff & Proprietary \\
\hline VG & $1 \mathrm{D}$ & Water/Chemical & C \& Fortran & Finite Diff & Open \\
\hline MERES & 1D & Vegetation/Water/Chemical & & Finite Diff & \\
\hline Pumpanen Model & $1 \mathrm{D}$ & Chemical & JAVA & Finite Diff & \\
\hline CoupModel & 1D & Moisture/Temperature & Fortran & Finite Diff & Open \\
\hline SNTHERM & 1D & Snow & Fortran & Finite Diff & Open \\
\hline Benoit & $1 \mathrm{D}$ & Snow & & Finite Diff & \\
\hline SHAW & 1D & Vegetation/Snow/Temp/Water & Fortran 90 & Finite Diff & Open \\
\hline SOIL & 1D & Snow/Water/Vegetation & Fortran 90 & Finite Diff & Proprietary \\
\hline Gusev & $1 \mathrm{D}$ & Snow & & Finite Diff & \\
\hline SCS & $1 \mathrm{D}$ & Water & Matlab & Finite Diff & Open \\
\hline Philip's Two-Term & $1 \mathrm{D}$ & Water & Matlab & Finite Diff & Open \\
\hline $\begin{array}{l}\text { Layered Green } \\
\text { Ampt }\end{array}$ & $1 \mathrm{D}$ & Water & Matlab & Finite Diff & Open \\
\hline Explicit Green Ampt & 1D & Water & Matlab & Finite Diff & Open \\
\hline $\begin{array}{l}\text { Constant Flux } \\
\text { Green Ampt }\end{array}$ & 1D & Water & Matlab & Finite Diff & Open \\
\hline 2DFATMIC & $2 \mathrm{D}$ & Chemical/Water/Temp & Fortran & Finite Ele & Open \\
\hline 3DFATMIC & $3 D$ & Chemical/Water/Temp & Fortran & Finite Ele & Open \\
\hline SEWAB & $?$ & Water/Temp/Veg & & Finite Diff & Proprietary \\
\hline
\end{tabular}




\section{Vegetation and Water Models}

Vegetation and water models are defined in this report as models that describe the physical and radiative processes occurring in the natural biophysical layer of the earth. In the review, we have identified two major groups of models that describe the spectral and thermal processes; vegetation and water.

\section{Vegetation Models}

The vegetation models reviewed for this report were classified into three categories; modeling spectral reflectance, leaf and canopy temperature, and moisture transport. Vegetation has a large impact on the exchange of energy and matter between the landscape and the atmosphere, as it changes the heating and cooling of surfaces during the day and in the processes of photosynthesis drives the fixation of carbon dioxide in plants and the evapotranspiration of water (Verhoef and Bach 2003). Vegetation density has a large impact on the spectral and thermal signature of the landscape and varies with view angle. The chlorophyll concentration of the vegetation determines the reflectance in the visible spectrum and vegetation moisture has a large effect on spectra in the thermal wavelengths.

\section{Vegetation reflectance models}

Vegetation canopy reflectance observed from airborne sensors differs greatly from reflectance measured from single leaves due to background reflectance mixing, and self-shadowing of the individual leaves in the canopy. Numerous studies of these effects have been conducted and models have been developed to describe these and other reflectance phenomena. Models reviewed for this study are listed in Appendix B.

Models for reflectance and hyperspectral modeling of vegetation are typically data driven (Kimes and Kirchner 1982, Verhoef 1984, Liang et al. 1997, Hanan 2001, Ballard and Smith 2002a, Ballard and Smith 2002b, Verhoef and Bach 2003) and vary in complexity from a geometric optical model to a volume-scattering medium of finite scattering elements in layers. These models describe the directional scattering behavior of the leaf canopies and evaluate the 
effects of sun-view geometry and soil on bi-directional reflectance (Ranson et al. 1985). Single element reflectance and directional field measurements were obtained and compared with model predictions. Of the models reviewed in this study, the Verhoef and Bach (2003) work appears most suitable for modeling the vegetation reflectance signatures in a natural landscape for conceptual wavelengths of developing mine detection sensors at the NVESD.

\section{Vegetation thermal models}

Background. Early work in developing a foliage/leaf temperature model was reported by H. Penman in 1948 (Allen 1986) as a study to estimate evapotranspiration by using properties of air and solar radiation to eliminate the need to directly measure crop temperatures. This ability to model daily evapotranspiration accurately is important in irrigation planning and scheduling water resources for crops (Allen 1986). The model Penman described was composed of three energy sources: convection, radiation, and evapotranspiration. Convection is the energy lost from a leaf by the cooling effect of the wind or the fluttering of the leaf (Oke 1992). Radiation is the energy either absorbed or emitted by the leaf from diffuse and direct solar, atmospheric, and ground radiation. Evapotranspiration consists of evaporation of water transpired from the leaves. This transpiration is a by-product of photosynthesis and is important since the water loss allows moisture and nutrient movement within the plant (Oke 1992). During the night, with a lack of direct solar radiation, photosynthesis is stopped, which in turns shuts down transpiration. Later work by Gates et al. (1968) applied and extended the Penman model to study leaf temperatures of desert plants. By studying the evaporative and convective properties of several species, they were able to provide theoretical justification to extend the model to characterize the plants' survival. In additional work by Alderfer and Gates (1971), they applied their model as a submodel to represent the exchange of energy within a one- to four-layered crop canopy where each layer was treated as a large set of leaves (Figure 3).

Discussion. Vegetation has a complex geometric structure (from grass to forests) that can contain extreme amounts of thermal variability depending on the surrounding heat fluxes. Components of the vegetation can respond quickly (1-2 seconds) to rapid solar loading changes (leaves) while other components change slowly (trunks). Figure 4 is a close-range thermal image $(800-1400 \mathrm{~nm})$ of a mine surrogate located in a grass/weed area. During a clear sunny summer day, the metal surface of the mine heats quickly and is easily discriminated from the surrounding grass, but on cloudy or rainy days the thermal differences are less than $1 \mathrm{deg} \mathrm{C}$. 


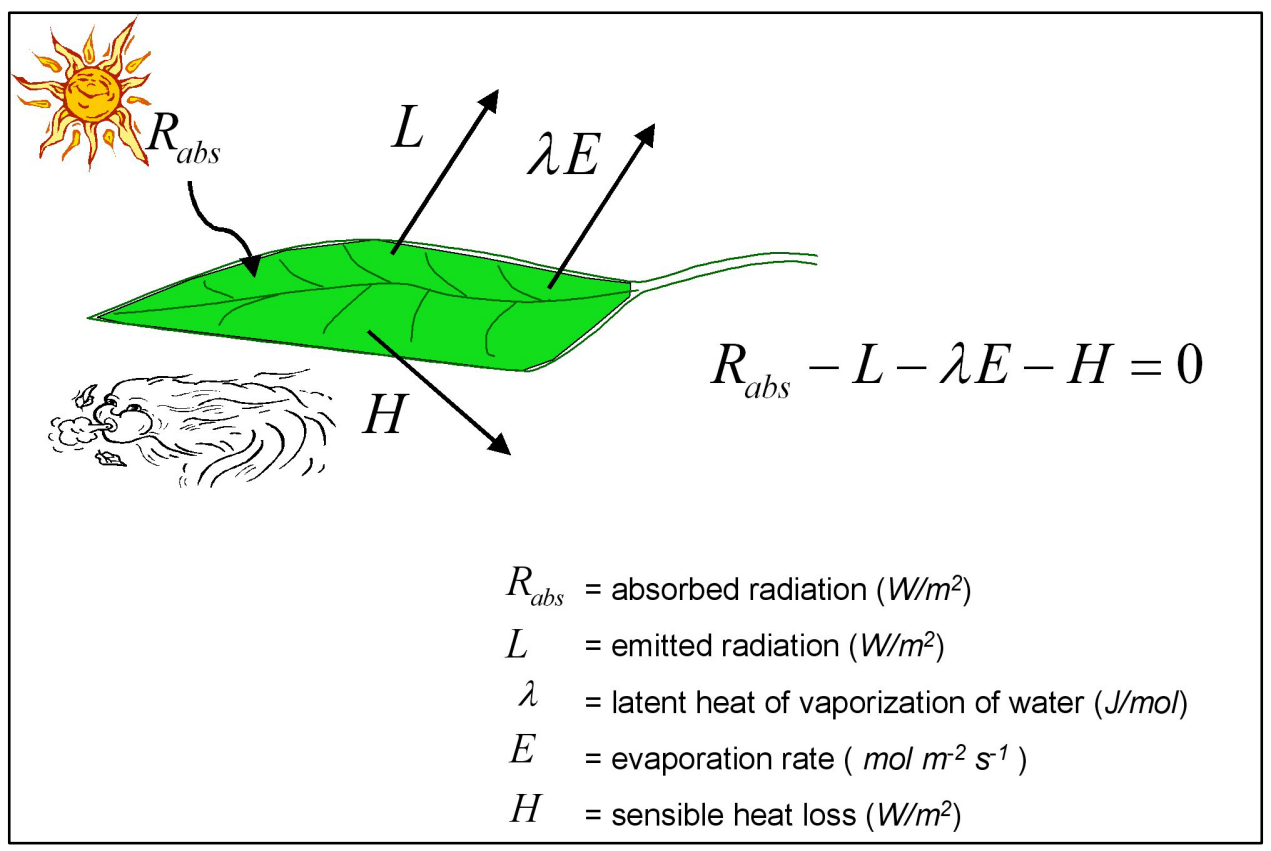

Figure 3. Energy balance of a single leaf

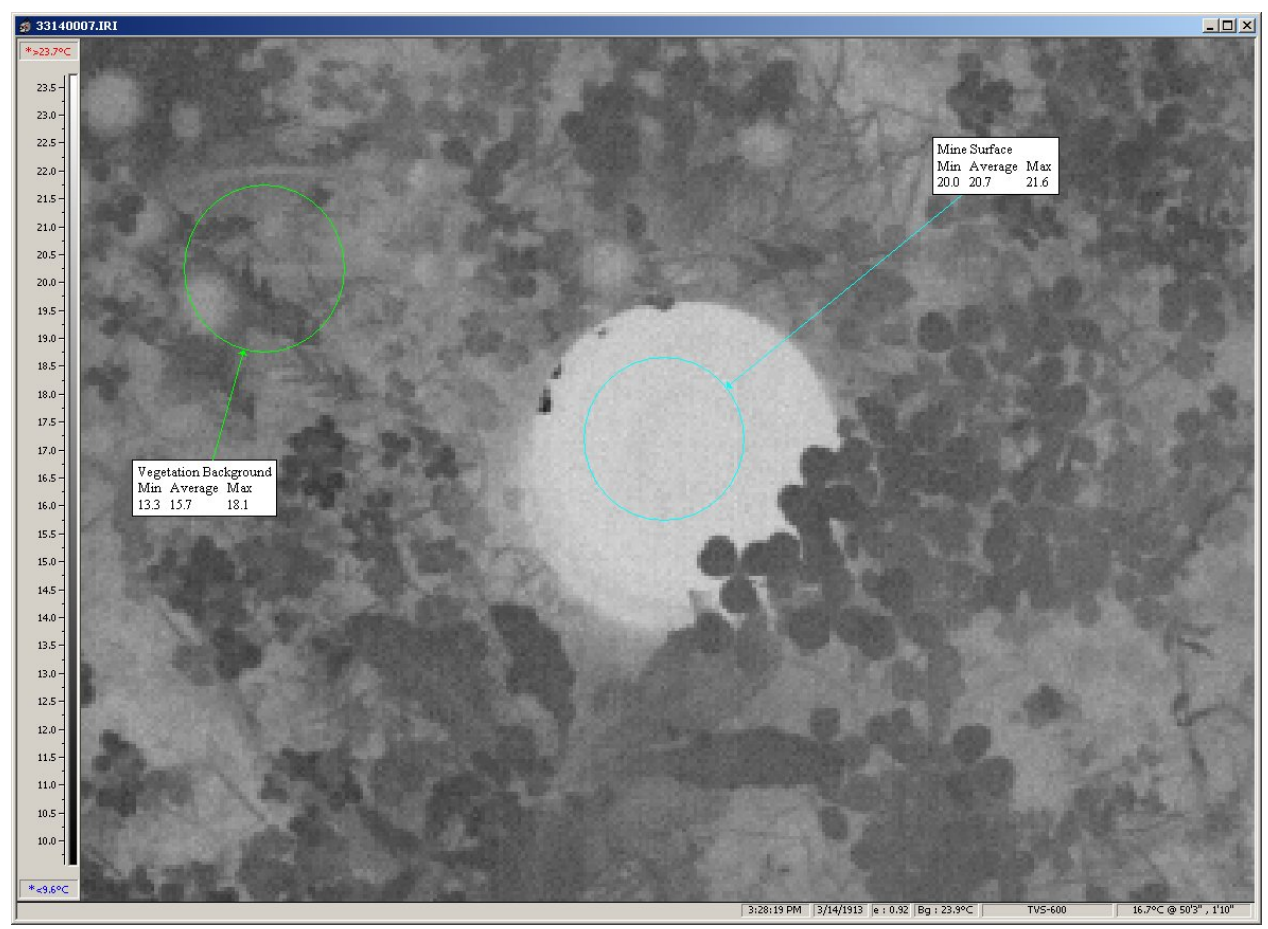

Figure 4. Estimated temperature differences in a healthy vegetated (grass) background

Vegetation not only has a complex geometric structure that is difficult to characterize but it responds quickly to changes of air temperature that arise from turbulence. Points in images of grass surfaces, for example, have been observed to change more than $10 \mathrm{deg} \mathrm{C}$ in a few seconds in an obviously spatially structured way (Ballard et al., in preparation). An image is a snapshot taken in 
this temporally varying background where an image a few seconds later can look considerably different (Figure 5). As a practical matter, modeling of the mean (scale of a few minutes) but still dynamic energy fluxes at the soil interface can be separated from the small-scale, rapid turbulence effects.

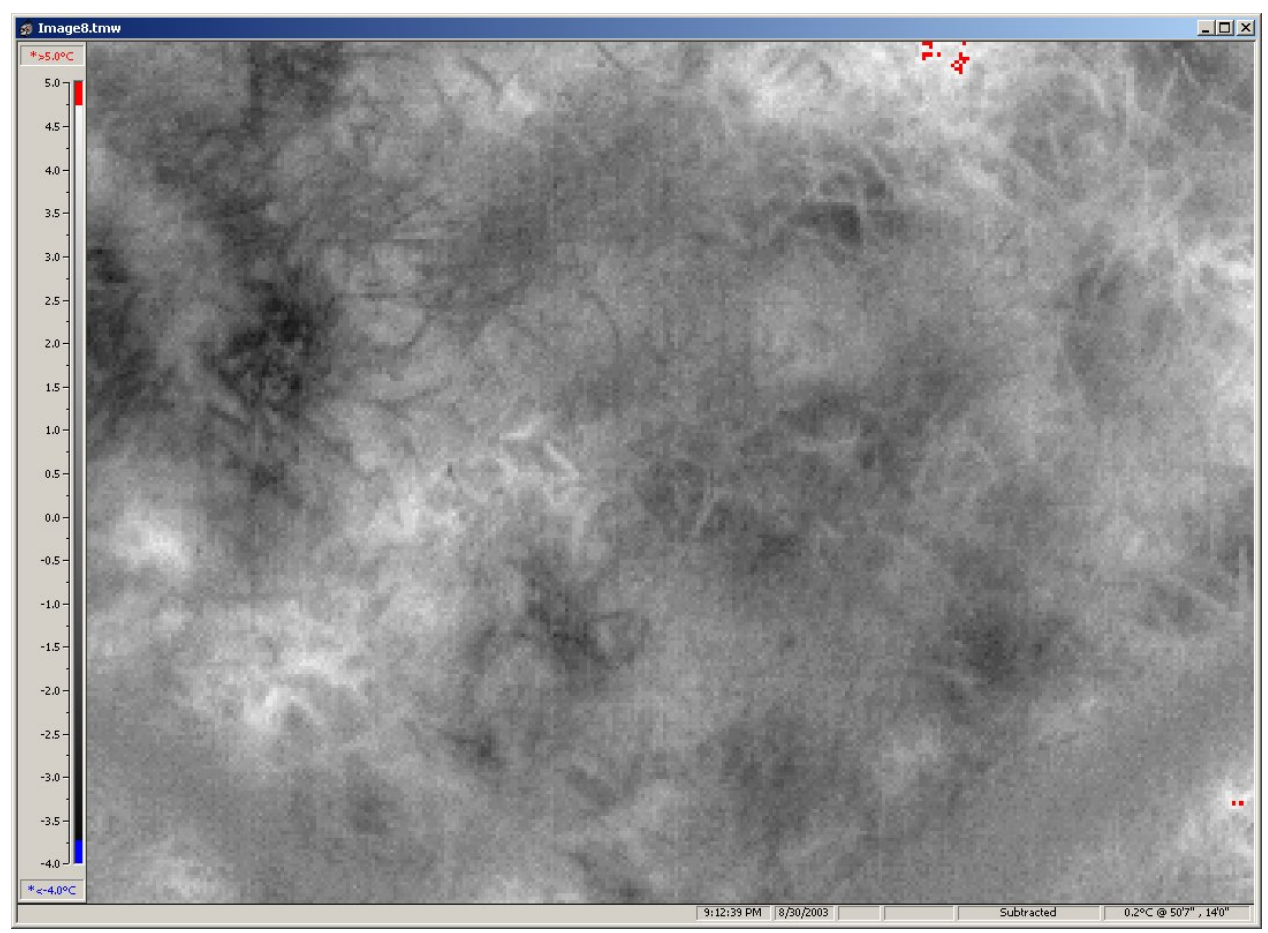

Figure 5. Observed temperature differences between two grass thermal (8-14 $\mu \mathrm{m}$ ) images collected $20 \mathrm{sec}$ apart. Width of the image on the ground is approximately $1 \mathrm{~m}$

While turbulence can have a major impact on an image (extremely important to the mine detection problem), short-term fluctuations probably have little impact on the net energy transfer into or out of the soil. Modeling mean conditions at longer time scales ( $>\sim 2-3$ minutes) seems adequate for soil energy/mass flux simulation. Events affecting the atmospheric energy fluxes such as cloud shadows, tree or building shadows, heavy dust or smoke can be important but are generally not included in modeling mine signatures. The importance of good simulations of the energy fluxes at the soil/atmosphere interface, and the lowest few centimeters of the atmosphere should not be underestimated, as their values and variability are large compared to fluxes within the soil.

Applicable models. Many vegetation thermal models have been developed, but basically all are derived from the Penman energy balance model. This basic modeling framework has improved along with improvements in calculating convection, stomatal resistance (Jarvis 1976), and evapotranspiration rates. Vegetation thermal models are listed in Appendix B. A discussion of vegetation thermal models follows. 
Balick et al. (1981b) coupled a vegetation model for simple short canopies such as lawns and pastures to a terrain surface temperature model (Balick et al. 1981a). In this model the vegetation is an optically opaque layer with holes in it and the air in the canopy is a weighted mixture of soil, canopy, and air characteristics. The model keeps track of separate energy budget equations for the ground and foliage. This model was recommended by earlier studies (Balick et al. 1990) for use in thermal infrared sensor simulations.

For more complex vegetation canopies, the Thermal Vegetation Canopy Model (TVCM) developed by Smith et al. (1981) is applicable for both conifer and deciduous forest canopies. The model is a plane-parallel abstraction of a vegetation canopy divided into horizontal layers and assumed steady-state conditions.

For individual trees, the model Treetherm (Hummel et al. 1991) provides a three-dimensional thermal response of an individual tree to its surrounding environment. The trees are represented as solid geometric shapes, such as cylinders and truncated cones, to represent the tree trunks and branches. The material distribution within each element is then established and material properties are assigned. A finite difference calculation of the energy budget is performed where the tree elements are allowed to interact with one another as well as the outside environment. For shrubs and plants, Dauzat et al. (2001) provide a simpler model.

\section{Vegetation moisture models}

Rapid changes in vegetation moisture content can change electromagnetic energy of the vegetation signature. Vegetation models are typically used to model water content, flow, and water potential in the plants and relate them to physiological processes, such as photosynthesis and leaf growth. The model can divide the plant up into components: roots, trunk, branches and twigs, and leaves. The soil-root interface and atmosphere form the boundaries and water is assumed to flow from root surface to atmosphere via a gradient of potential through a series of resistances.

Most of the vegetation models reviewed are associated with either agricultural research (Edwards et al. 1986, Granier et al. 2000, Dauzat et al. 2001) or global weather modeling (Kumagai 2001). These vegetation moisture models can clearly improve the understanding of the physiological processes of the vegetation as it responds to moisture and drought. Models reviewed are listed in Appendix B and summarized in Table 4. 


\begin{tabular}{|c|c|c|c|c|}
\hline \multicolumn{5}{|c|}{$\begin{array}{l}\text { Table } 4 \\
\text { Vegetation Models }\end{array}$} \\
\hline Model Name & Dimensions & Type & Availability & $\begin{array}{l}\text { Implementation } \\
\text { Potential }\end{array}$ \\
\hline $\begin{array}{l}\text { Thermal Vegetation } \\
\text { Canopy Model }\end{array}$ & $1-D$ & $\begin{array}{l}\text { Canopy Optical } \\
\text { and Thermal IR }\end{array}$ & Source & High \\
\hline CUPID & $1-D$ & $\begin{array}{l}\text { Soil-Plant- } \\
\text { Atmosphere }\end{array}$ & Source & Medium \\
\hline $\begin{array}{l}\text { Hyperspectral } \\
\text { Canopy } \\
\text { Reflectance Model }\end{array}$ & $3-D$ & $\begin{array}{l}\text { Canopy } \\
\text { Reflectance }\end{array}$ & Equations & Low \\
\hline $\begin{array}{l}\text { Enhanced Land } \\
\text { Surface } \\
\text { Discontinuous } \\
\text { Canopy Model }\end{array}$ & $1-D$ & $\begin{array}{l}\text { Surface and } \\
\text { Canopy } \\
\text { Reflectance }\end{array}$ & Equations & Low \\
\hline $\begin{array}{l}\text { Tree Temperature } \\
\text { Model }\end{array}$ & $3-D$ & Tree Thermal IR & Source/Equations & Medium \\
\hline $\begin{array}{l}\text { SAIL Canopy } \\
\text { Reflectance Model }\end{array}$ & $1-D$ & $\begin{array}{l}\text { Canopy } \\
\text { Reflectance }\end{array}$ & Source/Equations & High \\
\hline $\begin{array}{l}\text { Leaf Temperature } \\
\text { Model }\end{array}$ & $1-D$ & Leaf Thermal IR & Source & High \\
\hline $\begin{array}{l}\text { Tree Sapwood } \\
\text { Model }\end{array}$ & $1-D$ & $\begin{array}{l}\text { Tree Water } \\
\text { Transport and } \\
\text { Storage }\end{array}$ & Equations & Low \\
\hline $\begin{array}{l}\text { Plant Transpiration } \\
\text { and Sap Flow } \\
\text { Model }\end{array}$ & $3-D$ & $\begin{array}{l}\text { Plant Water } \\
\text { Transport and } \\
\text { Transpiration }\end{array}$ & Equations & Medium \\
\hline $\begin{array}{l}\text { Vegetation Canopy } \\
\text { Terrain Model }\end{array}$ & $1-D$ & $\begin{array}{l}\text { Soil-Vegetation } \\
\text { Thermal IR }\end{array}$ & Source/Equations & High \\
\hline
\end{tabular}

\section{Water Models}

Heat and mass transfer between the water surface and the atmosphere are of great importance, particularly after heavy rain events or heavy dew that can dramatically alter the spectral and thermal signatures of the water surface. In large water bodies, when there is a net heat loss through the water surface, the temperature of the surface skin is lower, by a few degrees, or fractions of a degree, than the bulk temperature measured at lower depths. The skin temperature can be estimated by infrared remote sensing through knowledge of the water surface emissivity, but other factors contribute to the variability in the skin surface temperature such as windspeed, drag coefficient, kinematic viscosity, and thermal diffusivity of the water (Oppenheimer 1997). These changes can be significant for spectral or thermal sensors. An example of this is shown in Figures 6 and 7 where during a field test, large amounts of rainfall filled in road depressions and caused significant changes in the landscape signature. 


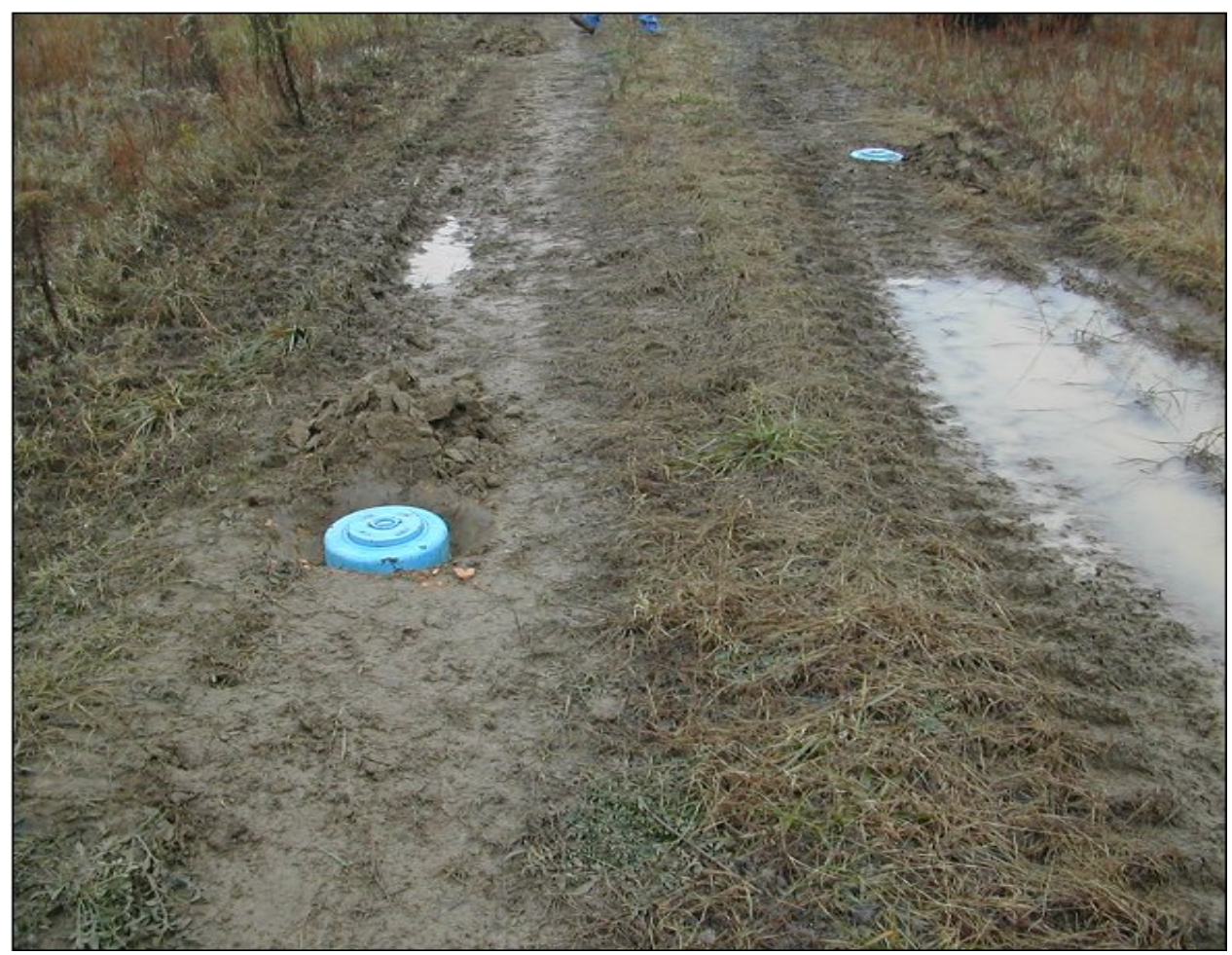

Figure 6. Wet soil and surface water conditions during a field test (Miller 2003)

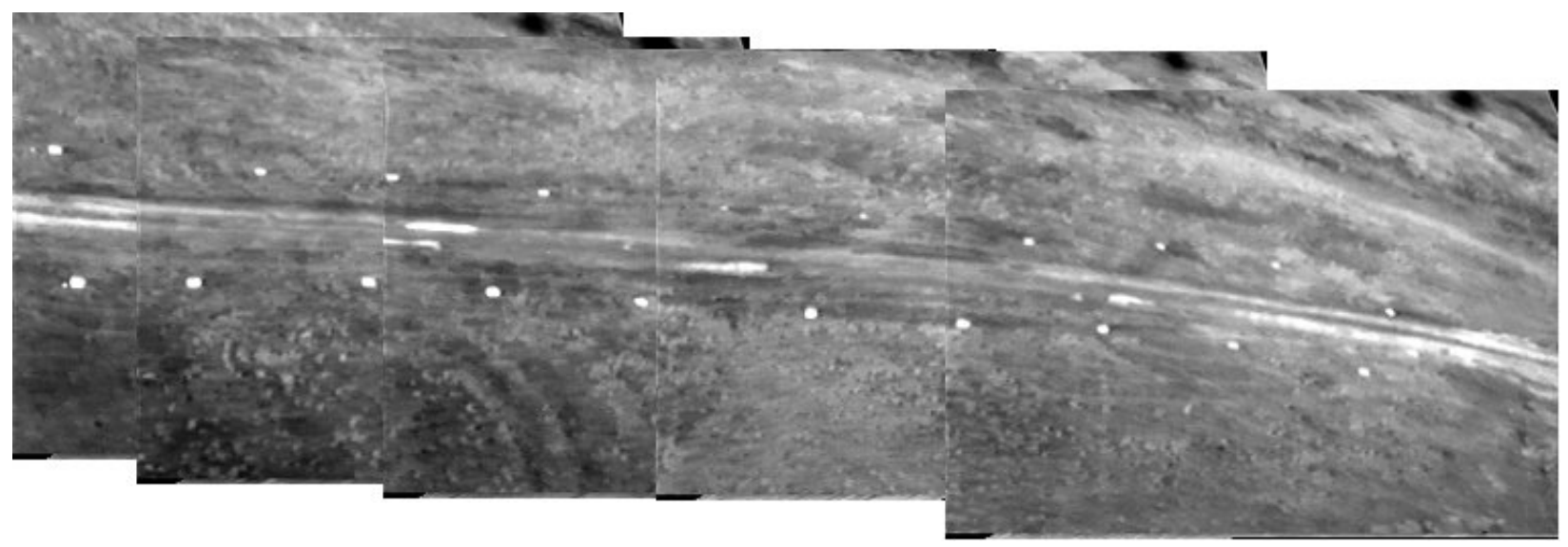

Figure 7. Overhead image of road with standing water (Miller 2003)

Numerous heat and mass transfer water feature models are available from the literature, where the majority of the models are concerned with contaminant and sediment transport and temperature is a by-product of the calculations. Possible models or equations identified that could be useful for generating signatures for sensors are found in a Tennessee Valley Authority report (1972) and the CEQUAL-W2 documentation (Cole and Buchak 1995).

CE-QUAL-W2 is a two-dimensional water quality and hydrodynamic code supported by the U.S. Army Engineer Research and Development Center (Cole and Buchak 1995, Wells and Cole 2000) and is commonly used in the Corps of 
Engineers studies. The model has been widely applied to stratified surface water systems such as lakes, reservoirs, and estuaries and computes water levels, horizontal and vertical velocities, temperature, and 21 other water quality parameters (such as dissolved oxygen, nutrients, organic matter, algae, $\mathrm{pH}$, the carbonate cycle, bacteria, and dissolved and suspended solids). 


\section{Atmospheric Models}

The atmosphere is that part of the Earth's gaseous environment that is held close by its gravity. The density of the atmosphere decreases with height above Earth's surface, and the temperature and composition also vary with altitude. The atmosphere consists of several regions, or altitude ranges, having different properties (temperature, pressure, and composition), which vary with altitude in different ways. In certain wavelengths, the atmosphere is clear while it is opaque in others. The clear wavelengths ("windows") that are commonly used are in the visible, 300- to 500-nm, and 800- to 1400-nm bands. Atmospheric models provide information on transmissivity, clouds, temperature, wind, and radiative features, which in turn change landscape signatures.

This chapter provides a list and reviews relevant atmospheric models that affect changes in landscape conditions. The general state parameters used in atmospheric models reviewed are shown in Table 5.

\begin{tabular}{||l|l||}
\hline \multicolumn{2}{|l|}{$\begin{array}{l}\text { Table } 5 \\
\text { General State Parameters Used in Atmospheric Models }\end{array}$} \\
\hline \hline \multicolumn{2}{|c|}{ General Atmospheric Variables } \\
\hline \hline \multicolumn{2}{|c|}{ Units } \\
\hline \hline Temperature Parameter & Degrees Celsius \\
\hline Dew point & Degrees Celsius \\
\hline Barometric pressure & Pascals \\
\hline Relative humidity & Percent \\
\hline Visibility (due to haze) & Kilometers \\
\hline Haze type (AKA extinction type) & Enumerated \\
\hline Wind (3 vector) & Meters/second \\
\hline Cloud cover & Fraction \\
\hline Cloud base & Meters \\
\hline Cloud top & Meters \\
\hline Cloud type & Enumerated \\
\hline Precipitation rate & Snow/rain \\
\hline Precipitation type & Mm/hr \\
\hline \hline & \\
\hline \hline Surface duct height & Meters \\
\hline Surface duct intensity & Enumerated \\
\hline Evaporative duct height & Meters \\
\hline Evaporative duct intensity & Enumerated \\
\hline Surface refractivity & \\
\hline
\end{tabular}


Previous studies by the Army to identify atmospheric models and databases to support combat simulations (Piwowar et. al. 1996) provided a list of atmospheric models. A later report, funded by the Defense Mapping and Simulation Office (DMSO), provided an additional general summary of the existing atmospheric models (Burgeson et al. 1996). The DMSO study identified 65 Air Force models, 31 Army models, and 61 Navy models. These models included atmospheric and near-space-environment models and databases along with environmental effects models and databases. The DMSO study suggests that 50 percent of the atmospheric models provided information on sensors, and 25 percent of the models provided atmospheric effects on military platforms. Few of these models (less than 10 percent) provided information on near-spaceenvironment data capabilities.

In the review of atmospheric models, we considered surface atmosphere models that supported high spatial resolutions of $100 \mathrm{~m}$ or less and high temporal resolutions. Table 6 summarizes the models that can be used to represent the effect of the atmosphere on landscape signatures.

\begin{tabular}{|l|l|l|l||}
\hline \hline \multicolumn{4}{||l||}{$\begin{array}{l}\text { Table } 6 \\
\text { Reviewed Atmospheric Models }\end{array}$} \\
\hline \hline Model & Dimensions ${ }^{1}$ & Model Description & Company \\
\hline \hline FASE & 1D & $\begin{array}{l}\text { Atmospheric } \\
\text { radiation/transmittance }\end{array}$ & Phillips Laboratory \\
\hline MODTRAN4 & 1D & $\begin{array}{l}\text { Transmittance/background } \\
\text { radiance }\end{array}$ & Phillips Laboratory \\
\hline MOSART & 1D & $\begin{array}{l}\text { Atmospheric } \\
\text { radiation/transmittance }\end{array}$ & Phillips Laboratory \\
\hline AGRMET & 3D & Surface soil conditions & AFGWC \\
\hline SNODEP & 2D & Snow & AFGWC \\
\hline SFCTMP & 2D & Surface temperature & AFGWC \\
\hline TRONEW & 3D & Cloud model & AFGWC \\
\hline DATSAV2 & 1D & Surface observations & USAFETAC/OL-A \\
\hline LOWTRN & 1D & Thermal transmittance & AMSRL-BE-SA \\
\hline $\begin{array}{l}\text { SOCUS } \\
\text { SOD }\end{array}$ & Acoustic propagation model & $\begin{array}{l}\text { Naval Oceanographic } \\
\text { Office }\end{array}$ \\
\hline OASES & 4D & Wind, rain, cloud cover & DMSO \\
\hline TAOS & 4D & Wind, rain, cloud cover & DMSO \\
\hline \hline $\begin{array}{l}\text { 1 Atmospheric dimensions. 1D indicates equations reflect changes due to a vertical column; 2D } \\
\text { indicates equations take into account horizontal and vertical components; 3D indicates modeling } \\
\text { of adjacent cells spatially; 4D indicates topography is included in the changes in movement of } \\
\text { atmospheric cells; time is always included in these calculations. }\end{array}$ \\
\hline \hline
\end{tabular}

Models such as MODTRAN4 model the reflectance, emittance, and absorption of the atmosphere. Models such as TAOS and OASES model the movement of clouds, low and high pressure zones, and wind fluctuations. Both types of models are important in determining the effect of the atmosphere on landscape signatures, but for simple short-term, line-of-sight airborne sensor studies, MODTRAN4 is recommended. 


\section{Recommendations and Discussion}

\section{Recommendations}

Specifically, the models recommended in this report are ones that are applicable to conceptual wavelengths of airborne mine detection sensors in development at the NVESD. Many models are available to predict temperature and moisture profiles in soils, vegetation, and atmosphere but questions of scale (time and space) and dimensionality (1D-3D) are non-trivial.

For a physics-based understanding of the natural environment and its impact on sensors, the following recommendations are made:

a. Soil. Use the simulation of transient or steady-state, density-dependent flow field described by the 3-Dimensional Subsurface Flow and Fate and Transport of Microbes and Chemicals (3DFATMIC) model (Yeh et al. 1997) and other similar models.

\section{b. Vegetation.}

(1) Reflectance. Use spectral models from Kimes and Kirchner (1982), Verhoef (1984), and Verhoef and Bach (2003).

(2) Thermal. For large-area, short canopies, use Balick et al. (1981b), for complex vegetation canopies, use Smith et al. (1981), for large individual trees, use Hummel et al. (1991), and for small plants/shrubs, use Dauzat et al. (2001).

(3) Moisture. Algorithms for water flow model for trees (Edwards et al. 1986) or water balance for forests (Granier 1994).

c. Water. Use algorithms from the CE-QUAL-W2 (Wells and Cole 2000).

d. Atmospheric. Use the moderate resolution transmittance (MODTRAN4) model for atmospheric transmittance and emittance (Air Force Research Laboratory 2003). 


\section{Discussion}

Critical short-tem requirements are to develop a realistic comprehensive modular framework that integrates existing phenomenological models. The integration should be done carefully and rationally as a system and involve scientists from multiple disciplines; preferably not by taking one partial model and adding features. The modular framework for models needs to be designed to operate in extreme climates from deserts to the tropics to arctic regions. Still, there are several real factors that have not as yet been well incorporated into models. These factors include:

- Realistic spatial variation of soil properties (including stones and rocks).

- Changes from the placement of buried mines, the thermal appearance of, and line-of-sight through, vegetation and vegetation modulation of energy fluxes to and from the soil.

- Effects of small-scale temperature fluctuations in thermal imagery and mine detection.

- Changes in the atmospheric environment such as large eddy wind gusts and cloud.

- Large-scale changes of soil moisture from changes of groundwater flow.

- Seasonal changes in soil properties including freeze/thaw impacts and active versus senescent vegetation impacts.

The ability to include these factors varies widely, and the scientific issues associated with each of them require research and definition.

When assembled, a model including all these factors will be extremely large and complex, and full of nonlinear interactions between processes. It will be difficult to understand the results in detail, and it will be difficult to validate. Furthermore, getting accurate input data to drive such a model will be a large issue for the simulation of real conditions for validation or possible operational use. Simulations for "typical" conditions are, in concept, easier but the inputs are not uncorrelated so care must be taken in using the model even for simple studies. All this complexity and requirements for input data calls into question whether a comprehensive supermodel is worth the investment. Given that it is worthwhile, component models need to be well understood and should be kept running in some simpler form to add insight into the calculations performed by the large model. Furthermore, modeling should include some measures of variability to assure its applicability over a search area.

Continuing research is needed primarily in the areas of vegetation effects of energy/mass transfers and mine detection in vegetated backgrounds and also the modeling of energy, liquid water, and gas fluxes in a spatially varying, realistic soil volume.

Other considerations on the effectiveness of models are the technical and programmatic objectives for the model. At one extreme are "science models," which describe in detail the physically important processes, but that require intensive inputs that are not operationally available. They may, or may not, abstract the physics or conditions to the point where certain physical processes are clear, but they do not represent reality. At the other extreme are "operational 
models," which try to simulate real observable processes in realistic conditions, with minimal effort and expertise. These models are intended to simulate real target signatures and, hopefully, backgrounds and must produce realistic estimates of target signatures and background variability. While the goal may be to simplify the physics, the real geoenvironment is very complex and variable; model complexities shift from detailed treatment of physical processes to detailed treatment of geoenvironmental conditions. Of course, most existing models exist between the two extremes. In any case, the need is to simplify or abstract reality with clearly defined objectives.

It is also important to include sensor models and detection algorithms in a comprehensive modeling system for thermal IR mine detection. The sensor modulates the signal predicted by the models, even for the simplest models. Signal-to-noise ratio is one useful measure, but the effects of the optical system on the signal are complex, especially for imaging systems. A useful detection model (or perhaps multiple detection models) is needed to objectively measure the performance of the model system, although human perception should not be discarded. These models are beyond the scope of this review but should not be ignored.

A comprehensive model of the thermal IR signatures and detectability of mines must consider a wide variety of physical processes and geoenvironmental conditions. For reasons discussed earlier, models tend to exist for subsets of processes or conditions. For discussion purposes, it is useful to separate major parts of the whole system into components on which discussions can be focused and broadly represent distinctions between models. Any such breakdown is necessarily arbitrary and models often cross these artificial boundaries. There is a rough progression of temporal variation from the bottom (some level beneath the surface) to the top (the local environmental conditions) and this discussion follows that progression. For the discussion, the following components of energy/mass transfer processes are discussed:

- Deep (>25 cm) soil.

- "Active" soil layer fluxes.

- Near-surface atmospheric fluxes (lowest few centimeters).

- Atmospheric boundary layer (the lowest few meters) fluxes.

- Effects of the general state of the atmosphere.

Furthermore, the approach taken is that the mine detection simulation problem is local and of short duration (indeed, any particular image is an instantaneous snapshot of changing temperature patterns) and that large-scale, slow processes can be considered as background or boundary conditions for the system. Finally, for simplicity, surface wetness effects (rain, dew) will not be considered.

In deep soils (usually $50 \mathrm{~cm}$ or greater below the surface) temperature changes slowly and heat transfer from groundwater movement is normally relatively steady in the absence of events such as rain or flooding. These processes might be considered as background or boundary conditions, but having a good handle on them is important since soil moisture distribution and movement are major factors controlling thermal IR mine detection. These models 
do usually include heat and mass fluxes in the active or near-surface soil layer, but generally not at the level of detail as those designed to simulate fluxes in and around buried mines. Given the strong interest in groundwater and pollution transport, several models have been developed to describe these processes and they are active areas of research. These models have not been reviewed for this report.

The thermally active layer of the soil is the layer that contains buried mines so that detailed 3-D simulation of energy and mass fluxes are desired. The most comprehensive models imbed a mine in a 3-D finite element (or difference) grid and simulate the perturbation of fluxes due to the mine. Normally, the soil around the mine is uniform or highly idealized. The real impact of these abstractions does not seem to have been thoroughly investigated or reported. Models performing detailed simulations of energy and mass fluxes in a soil/mine volume are necessarily complex. Processes involved include temperature diffusion through solids, liquid water transport, water phase changes and vapor transport, and non-vapor gas transport. These are coupled nonlinear processes requiring large computer resources to simulate in detail. While each of these processes can and has been well simulated, no mine detection model has been found to integrate all these processes. For the simulation of active layer heat and moisture transport applied to the mine detection problem, the work by a group at Ohio State University stands out as the most comprehensive. The last report of the work at Ohio State listed integration of submodels as something that needed to be done and this work may well be underway. The Ohio State model uses a simplified parameterization of energy fluxes at the surface boundary, understandable for their model, but not sufficient for a comprehensive model for thermal IR mine detection. Mine simulation work has been initiated at the Georgia Tech Research Institute. While documentation of this program is still limited, it does show a comprehensive approach with good attention to realism. The Georgia Tech program is part of a recent ARO MURI program. Other models have been developed, often by researchers studying specific phenomena. In summary, integration of models for the individual energy and mass transport processes are available but apparently not yet integrated. The input requirements for such an integrated model may be large, perhaps too large to be used operationally. Also, the models simulate rather ideal conditions for both the soil properties and the air/surface energy transfers.

The surface layer is what the sensor observes and the source of much of the background against which the mine must be detected. Therefore, its properties must be well represented in a comprehensive model. Furthermore, it is a very dynamic boundary condition for simulations of energy and mass transfer within the active layer of the soil. This discussion makes a rather arbitrary distinction between the static physical surface properties and the dynamic energy/mass fluxes near the surface. Static properties include surface roughness, spatial variation of surface properties (especially emissivity), and herbaceous vegetation/litter. Each of these adds complexity to the background of the mine thermal anomaly at the surface and impairs detection. The Ohio State University group has made solid modeling efforts to simulate the effects of roughness and emissivity variation on background variability at scales appropriate to the mine detection problem. Others have addressed these complexities as well, but none stand out as being better. 
The physics of the temperature anomalies due to buried objects (like mines) is a complex system of nonlinear, coupled energy and mass fluxes. Detailed simulation of even subsets of these fluxes has proven a daunting task. As is often the case, 80-90 percent of the answer can be achieved simply and cheaply, but that last 10 or 20 percent is difficult. Simple models have been available for years. More sophisticated models are under development or available elsewhere, but some aspects of remotely detected anomalies due to the presence of mines are not well understood. 


\section{References}

Ackenhusen, J. G., Quentin A. H., King, C., and Wright, J. A. (2001). "Detection of mines and minefields," Technical Report 440000-217-T, Infrared Information Analysis Center, Veridian Systems, Ann Arbor, MI.

Air Force Research Laboratory (2003). "AFRL/VSSS MODTRAN 4 Software," Web Page, On-line [http://www2.bc.edu/ sullivab/soft/modtran4.html] from AFRL/VSSS, 29 Randolph Road, Hanscom AFB, MA 01731-3010. Accessed September 10, 2003.

Alderfer, R. G., and Gates, D. M. (1971). "Energy exchange in plant canopies," Ecology 52:854-861.

Allen, R. G. (1986). "A Penman for all seasons," Journal of Irrigation and Drainage Engineering 112:348-369.

Angelini, L., et al. (2001) "Chaotic neural network clustering: An application to landmine detection by dynamic infrared imaging," Opt. Eng. 40:2878-2884.

Army Science and Technology Master Plan (ASTMP). (1997). "Annex A. Science and Technology Objectives (STOs)” paragraph III.M.10.

Balick, L. K., Link, L. E., Scoggins, R. K., and Solomon, J. R. (1981a). "Thermal modeling of terrain surface elements," Technical Report EL-81-2, Environmental Laboratory, U.S. Army Engineer Waterways Experiment Station, Vicksburg, MS.

Balick, L. K., Scoggins, R. K., and Link, L. E. (1981b). "Inclusion of a single layer of vegetation in terrain temperature models for thermal infrared signature prediction." IEEE Transactions on Geoscience and Remote Sensing, GE-19(3): 143-152.

Balick, L. K., Hummel, J. R., Smith, J. A., and Kimes, D. S. (1990). “Onedimensional temperature modeling techniques: Review and recommendations," Smart Weapons Operability Enhancement Report 90-1, U.S. Army Cold Regions Research and Engineering Laboratory, Hanover, NH. 
Ballard, J. R., Jr., Berry, T. E., Leese, D. L., and Anderson, S. C. "High temporal infrared characterization of dense grass during high humidity conditions."

Proceedings for SPIE Conference OR42 Targets and Backgrounds X: Characterization and Representation, Orlando, FL, 12-16 April 2004. (In preparation).

Ballard, J. R., Jr., and Smith, J. A. (2002a). "Hyperspectral canopy reflectance modeling and EO-1 Hyperion." Proceedings for SPIE Conference 4725 on Algorithms and Technologies for Mulitspectral, Hyperspectral, and Ultraspectral Imagery VIII, Orlando, FL, 1-5 April, 2002.

Ballard, J. R., Jr., and Smith, J. A. (2002b). “A multi-wavelength thermal infrared and reflectance scene simulation model." Proceedings for 2002 IEEE International Geoscience and Remote Sensing Symposium, Toronto, Canada, June 24-28, 2002.

Burgeson, J. C., Piwowar, T. M., Try, D. D., Grantham, D. D., Brand, S., and Wetmore, A. E. (1996). "Natural environmental effects in military models and simulations: Part II - A survey of capabilities," PL-TR-96-2040, Phillips Laboratory, Air Force Materiel Command, Hanscom Air Force Base, MA.

Carin, L., ed. (2001). "Special issue on new advances in subsurface sensing: Systems, modeling and signal processing" (2001) IEEE Trans. Geosci. Remote Sensing, 39.

Cole, T., and Buchak, E. (1995). "CE-QUAL-W2: A two-dimensional, laterally averaged, hydrodynamic and water quality model, Version 2.0," Instruction Report EL-95-1, U.S. Army Engineer Waterways Experiment Station, Vicksburg, MS.

Conrad, R., Schultz, H., and Barbble, M. (1987). "Temperature limitation of hydrogen turnover and methanogenesis in anoxic paddy soil," FEMS Microbiol Ecol. 45:281-289.

Das, Y., McFee, J. E., and Cross, G., (2002). "Soil properties database for humanitarian demining: A proposed initiative," Paper presented to the Council of the International Union of Soil Science at the 17th World Congress of Soil Science, Bangkok, Thailand.

Dauzat, J., Rapidel, R., and Berger, A. (2001). "Simulation of leaf transpiration and sap flow in virtual plants: Model description and application to a coffee plantation in Costa Rica," Agricultural and Forest Meteorology 109, 143 160.

Dunfield, P., Knowles, R., Dumount, R., and Moore, T. R. (1993). "Methane production and consumption in temperate and subartic peat soils," Soil Biol Biochem 25, 321-326.

Edwards, W. R. N., Jarvis, P. G., Landsberg, J. J., and Talbot, H. (1986). “A dynamic model for studying flow of water in single trees," Tree Physiology 1, 309-324. 
Gates, D. M., Alderfer, R. G., and Taylor, E. (1968). "Leaf temperatures of desert plants," Science 159:994-995.

Granier, A., and Loustau, D. (1994). "Measuring and modeling the transpiration of a maritime pine canopy from sap-flow data," Agricultural and Forest Meteorology 71, 61-81.

Harmon, R. S., et al. (2003). SPIE Conference on Detection and Remediation Technologies for Mines and Minelike Targets VIII, Orlando, FL.

Hanan, N. P. (2001). "Enhanced two-layer radiative transfer scheme for a land surface model with a discontinuous upper canopy," Agricultural and Forest Meteorology 109:265-281.

Hummel, J. R., Jones, J. R., Longtin, D. R., and Paul, N. L. (1991). "Development of a 3-D tree thermal response model for energy budget and scene simulation studies," Technical Report LTR 91-002, SPARTA, Inc., Lexington, MA.

Jarvis, P. G. (1976). "The interpretation of the variations in leaf water potential and stomatal conductance found in canopies in the field," Phil. Trans. R. Soc. Lond. 273, 593-610.

Kendall, F. (2001). "Army Science Board and Naval Research Advisory Committee Joint Countermine Technologies Study," Final Report.

Kerner, D., Deni, J., Joseph, G., Churchill H., Johnson, R., and Kincaid., T. (1998). "Anti-personnel landmine (APL) detection technology survey and assessment - wide-area detection in support of arms control," DynMeridian, Alexandria, VA.

Kimes, D. S., and Kirchner, J. A. (1982). "Radiative transfer model for heterogeneous 3-D scenes,” Applied Optics 21(22):4119-4129.

Kumagai, T. (2001). "Modeling water transportation and storage in sapwood model development and validation," Agricultural and Forest Meteorology 109, 105-115.

Liang, S., Strahler, A. H., Jin, X., and Zhu, Q. (1997). "Comparisons of radiative transfer models of vegetation canopies and laboratory measurements," Remote Sensing of Environment 61:129-138.

MacDonald, J., et al. (2003). Alternatives for landmine detection. RAND MR1608-OSTP.

Matthews, R. B., Wassmann, R., and Arah, J. (2000). "Using a crop/soil simulation model and GIS techniques to assess methane emissions from rice fields in Asia; I. Model development," Nutrient Cycling in Agroecosystems 58: 141-159. 
Miller, M. (2003). "S\&T OAV 6.2 Summary," OAV Countermine Briefing, March 19, 2003.

Norman, J. M. (1979). "Modeling the complete crop canopy." Modification of the aerial environment of plants. ASAE Monogr., B. J. Barfield and J. F. Gerber, ed., Am. Soc. Agric. Eng., St. Joseph, MI, 249-277.

Oke, T. R. (1992). Boundary layer climates. Routledge, Chapman and Hall, Inc., New York.

Oppenheimer, C. (1997). "Remote sensing of the color and temperature of volcanic lakes," International Journal of Remote Sensing 18(1):5-37.

Piwowar, T. M., Burgeson, J. C., Paul, D. T., Donald, D. G., Brand, S., and Wetmore, A. E. (1996). "Natural environmental effects in military models and simulations: Part I - A survey of requirements," PL-TR-96-2029, Phillips Laboratory, Air Force Materiel Command, Hanscom Air Force Base, MA.

Ranson, K. J., Biehl, L. L., and Bauer, M. E. (1985). "Variation in spectral response of soybeans with respect to illumination, view, and canopy geometry," International Journal of Remote Sensing 6:1827-1842.

Schott, J. R., Brown, S. D., and Richardson, M. J. (2001). "The role of physical modeling and scene simulation in support of space based remote sensing." 2001 Core Technologies for Space Systems Conference Proceedings. Track II.

Smith, J. A., Ranson, K. J., Nguyen, D., and Link, L. E. (1981). "Thermal vegetation canopy model studies," Technical Report EL-81-6, prepared by Colorado State University in collaboration with the Environmental Laboratory, Waterways Experiment Station, for the U.S. Army Engineer Waterways Experiment Station, Vicksburg, MS.

Smith, J. A., and Ballard, J. R., Jr. (1999). "Effects of spatial resolution on thermal and near infrared sensing of canopies," Optical Engineering 38 (8), 1413-1423.

Smith, J. A., and Ballard, J. R., Jr. (2001). "Thermal infrared hot spot and dependence on canopy geometry," Optical Engineering 40 (8), 1435-1437.

Tennessee Valley Authority. (1972). "Heat and mass transfer between a water surface and the atmosphere," Tennessee Valley Authority, Laboratory Report No. 14, Report No. 0-6803, Norris, TN.

Van Dam, et al. (2003). "Effects of soil water content and texture on radar and infrared landmine sensors: Implications for sensor fusion." EUDEM2-SCOT Int'l Conf on Requirements and Technologies for the Detection, Removal and Neutralization of Land Mines \& UXO, Brussels. 
Verhoef, W. (1984). "Light scattering by leaf layers with application to canopy reflectance modeling: the SAIL model," Remote Sensing of Environment $16: 125-114$.

Verhoef, W., and Bach, H. (2003). "Simulation of hyperspectral and directional radiance images using coupled biophysical and atmospheric radiative transfer models," Remote Sensing of Environment 87, 23-41.

Wells, S. A., and Cole, T. M. (2000). “CE-QUAL-W2, Version 3," Water Quality Technical Notes Collection (ERDC WQTN-AM-09), U.S. Army Engineer Research and Development Center, Vicksburg, MS.

Witten, T. T. (1998). "Present state of the art in ground-penetrating radars for mine detection." Proc. SPIE Conf. Detection and Remediation Technologies for Mines and Minelike Targets III, Orlando, FL, 576-586.

Yang Zong-Liang, Y., and Dickinson, R. E. (1996). "Description of the biosphere-atmosphere transfer scheme (BATS) for the soil moisture workshop and evaluation of its performance," Global and Planetary Change 13(1-4), 117-134.

Yeh, G., Cheng, J., and Short, T. E. (1997). “3DFATMIC: User's Manual of a Three-Dimensional Subsurface Flow, Fate and Transport of Microbes and Chemicals Model: Version 1.0," EPA/600/R-97/053, National Risk Management Research Laboratory, Office of Research and Development, U.S. Environmental Protection Agency, Cincinnati, OH. 


\section{Bibliography}

Borchers, B., et al. "Modeling distributions of water and dielectric constants around landmines in homogeneous soils." Proc. SPIE conference on Detection and Remediation technologies for Mines and Minelike Targets IV, Orlando, FL.

Botkin, E., Krassner, M., Wise, K. S., Gawronski, G., and D Argenio, C. S. (1981). "Infrared modeling and analysis (IRMA) ENVIRO/SCNGEN (Program/Subroutine Description)," U.S. Air Force Armament Laboratory, Report No.1 AfTAL-TR-81, Hanscom AFB, MA.

Campbell, G. W., and Norman, J. M. (1998). An introduction to environmental biophysics. 2nd ed., Springer-Verlag Inc., New York.

Caron, B., Kay, D., and Kachanoski, R. G., (1992). "Modeling temporal changes in structural stability of a clay loam soil," Soil Science 56, 1597-1604.

Cathcart, J., Campbell, R., Bock, R., Karlowatz, M., Mizaikoff, B., and Orlando, T. (2003). "Impact of shallow buried objects on the spectral properties of terrain features." Proc. SPIE Conference on Detection and Remediation Technologies for Mines and Minelike Targets VIII, Orlando, FL, 614-624.

Chang, C.-I., and Chiang, S.-S. (2002). "Anomaly detection and classification for hyperspectral imagery," IEEE Trans. on Geoscience and Remote Sensing 40, 1314-1325.

Choudhury, B. J., Schmugge, T. J., Newton, R. W., and Chang, A. (1979). "Effect of surface roughness on microwave emission of soils," Journal of Geophysical Research 84, 5699-5706.

Choudhury, B. J., Schmugge, T. J., and Mo, T. (1982). "A parameterization of effective temperature for microwave emission," Journal of Geophysical Research 87: 1301-1304.

Clapp, R. B., and Hornberger, G. M. (1978). "Empirical equations for some soil hydraulic properties," Water Resource Research 14, 601-604. 
Dai, Y., Zeng, X., Dickinson, R. E., Baker, I., Bonan, G. B., Bosilovich, M. G., Denning, A. S., Dirmeyer, P. A., Houser, P. R., Niu, G., Oleson, K. W., Schlosser, C. A., and Yang, Z. L., (2003). "The common land model," Bulletin of the American Meteorological Society 84(3), 1013-1023.

Granier, A., Biron, P., and Lemoine, D. (2000). "Water balance, transpiration and canopy conductance in two beech stands," Agricultural and Forest Meteorology 100, (4), 291-308.

Hendrickx, et al. (2003). "Worldwide distribution of soil dielectric and thermal properties" Proc SPIE Conference on Detection and Rediation Strategies for Mines and Mineline Targets VIII.

Jackson, T. J., Le Vine, D. M., Swift, C. T., Schmugge, T. J., and Schiebe, F. R. (1995). "Large area mapping of soil moisture using the ESTAR passive microwave radiometer in Washita '92," Remote Sensing of Environment 53: 27-37.

Jordan, R. (1991). "A one-dimensional temperature model for a snow cover: Technical documentation for SNTHERM.89," Special Report 91-16, U.S. Army Cold Regions Research and Engineering Laboratory, Hanover, NH.

Kimes, D. S., Smith, J. A., and Ranson, K. J. (1979). "Terrain feature canopy modeling," Final report under U.S. Army Research Office Grant DAAG2978-G-0045, Colorado State University, Fort Collins.

Lyons, J. T. (1991). "SIRIM user reference manual," ERIM Report on Project 639713-1-X, ERIM, Ann Arbor, MI.

Newhall, F. (1972). "Calculation of soil moisture regimes from the climatic record," Revision 4, USDA Soil Conservation Service, Washington, DC.

Njoku, E. G., and Kong, J. A. (1977). "Theory for passive microwave remote sensing of near-surface soil moisture," Journal of Geophysical Research 82, 3108-3117.

Peplinski, N. R., Ulaby, F. T., and Dobson, M. C. (1995). "Dielectric properties of soils in the 0.3-1.3 Ghz range." IEEE Transactions on Geoscience and Remote Sensing. 33:803-807.

Wang, J. R., and Schmugge, T. J. (1980). "An empirical model for the complex dielectric permittivity of soils as a function of water content." IEEE Trans. Geosci. Remote Sensing. 18:288-295.

Wilheit, T. (1978). "Radiative transfer in a plane stratified dielectric." IEEE Trans. Geosci. Elec. GE-16, 138-143.

Wilson, M. F., Henderson-Sellers, A., Dickinson, R. E., and Kennedy, P. J. (1987a). "Sensitivity of the biosphere-atmosphere transfer scheme (BATS) to the inclusion of variable soil characteristics," Journal of Applied

Meteorology 26, 341-362. 
Zang, T. (1994). "Sensitivity properties of a biosphere model based on BATS and a statistical dynamical climate model," Journal of Climate 7, 890-913. 


\section{Appendix A Soil Models}

Model Name: Biosphere-Atmosphere Transfer Scheme (BATS)

Description: The BATS model utilizes information about the soil and upper vegetation to support various global circulation models. The model uses an extensive list of inputs, in part, because moisture and temperature correlations are considered. Boundary conditions between layers of the atmosphere and vegetation cover are also used to compute evapotransporation rates. The atmospheric model in BATS is defined from data read in sets describing distribution of land points, including elevation, sea ice coverage, and ocean surface temperatures. Sea ice coverage and ocean temperature can vary seasonally. A distribution of net energy fluxes over the ocean may also be predefined. Data are read for each land point describing dominant vegetation cover, soil texture, and soil cover. There are 18 predefined vegetation classes with the soil depth of interest set at 10 centimeters. There are 12 predefined soil classes with differing saturated hydraulic conductivity and residual moisture contents. Differential moisture flow between layers appears to be modeled.

Application: Global Weather and Climate Modeling Agency Point of Contact/Reference: Zong-Liang, Y., and Dickinson (1996).

Model Name: Global Environmental and Ecological Simulation of Interactive Systems (GENESIS)

Description: The GENESIS Earth Systems Model was developed by National Center for Atmospheric Research (NCAR) as a model of the Earth's climate system for global change research. GENESIS uses soil moisture migration equations defined by Clapp and Hornberger (1978). Six soil layers are defined to a depth of $4.25 \mathrm{~m}$. Heat is diffused linearly and appears to be based on ambient temperature fluctuations as opposed to correlations to soil moisture and radiating heat. The soil texture and albedo properties used in the model are based on a 1deg resolution database of sand/silt/clay fractions. Moisture is modeled in a onedimensional fashion. A chemical soil transport model is also included. The soil chemical transport model supports upward movement of the chemicals in the soil.

Application: Global Systems Modeling Agency Point of Contact/Reference: NCAR 
Model Name: Soil Fugacity Model

Description: The Soil Fugacity model was developed to provide a simple assessment of the relative potential for degrading reaction, evaporation, and leaching of a pesticide applied to a surface soil. The required inputs are the chemical name, temperature, molecular mass, water solubility, vapor pressure, organic carbon partition coefficient, Koc, mineral-water partition coefficient, degradation half-life, and chemical dosage. Soil inputs are soil area and depth, mean vertical diffusion distance from the middle of the soil layer to surface, volume fractions of air and water, mass fraction of organic carbon, and leaching rate. The model outputs include system fugacity, $\mathrm{Z}$ and $\mathrm{D}$ values, fluxes, concentrations and amounts in each compartment, and residence times. The model does not compute different leach times of the movement of chemicals to the surface due to changes in the tension of the soil. Different soil types are accounted for by defining different average permeabilities.

Application: Chemical Diffusion Agency Point of Contact/Reference: Canadian Environmental Modeling Center

Model Name: Transport/residing of chemicals in soil (CemoS) model Description: The CemoS model (transport/residing of chemicals in soil) model was developed by the Institute of Environmental Systems Research, University of Osnabrueck, Germany. The model is part of the model package CemoS, a program system for exposure concentration estimates of environmentally hazardous chemicals. CemoS/Soil is a dynamic model for the description of the transport and the residing of a chemical in a soil column. The model can be used in three situations:

- A single input of a chemical at the soil surface.

- Transport from a contaminated soil layer into deeper layers.

- Transport and residing in case of a continuous injection.

Besides the concentration profile of the chemical in the soil, the model calculates the fractions of the chemical in the soil-water, the soil-air, and the soil-matrix. Further outputs are the velocity of the vertical transport of the chemical and the total diffusion-/dispersion coefficient of the chemical in the soil.

Application: Chemical Diffusion Agency Point of Contact/Reference: Institute of Environmental Systems Research, Germany

Model Name: SESOIL Description: The SESOIL (SEasonal SOIL) compartment model is a onedimensional vertical transport code for the unsaturated soil zone. It is an integrated screening- level soil compartment model and is designed to simultaneously model water transport, sediment transport, and pollutant fate. SESOIL utilizes soil, chemical, and meteorological values as input. The model considers one compound at a time and is based on mass balance and equilibrium partitioning of the chemical between different phases (dissolved, sorbed, vapor, and pure). SESOIL was designed to perform long-term simulations of chemical transport and transformations in soil. SESOIL accepts time-varying pollutant loading and uses theoretically derived equations to represent water transport, sediment transport on the land surface, pollutant transformation, and migration of the pollutant to the atmosphere and groundwater. Climatic data, compartment geometry, and soil and chemical property data are the major components used in 
the equations. Output of SESOIL includes time-varying pollutant concentrations at various soil depths and pollutant loss from the unsaturated zone in terms of surface runoff, percolation to the groundwater, volatilization, and degradation. Application: Chemical and water diffusion, transport, and transformation. Agency Point of Contact/Reference: The program was developed for EPA's Office of Water and Office of Toxic Substances in 1984 by Marcos Bonazountas and Janet Wagner of Arthur D. Little, Inc., and was modified extensively in 1986 by David Hetrick of Oak Ridge National Laboratory (ORNL) to enhance its capabilities.

\section{Model Name: HYDROGEOCHEM}

Description: The purpose of HYDROGEOCHEM is to simulate transient and/or steady-state density-dependent flow fields and temperature distribution and to compute transient and/or steady-state distribution of reactive multispecies chemical concentrations in subsurface media.

HYDROGEOCHEM computes and predicts the distribution of pressure head, moisture content, flow velocity, and total head over a three-dimensional plane in completely saturated, completely unsaturated, partially unsaturated, or partially saturated subsurface media. It also computes and predicts the spatial-temporal distribution of multi-chemical components. The media may consist of as many types of soils and geologic units as desired with different material properties. Each soil type may be isotropic or anisotropic. The processes governing the distribution of chemical distribution include (1) geochemical equilibrium of aqueous complexation, reduction-oxidation, sorption, and precipitation and dissolution, and (2) hydrological transport by flow advection, dispersion, and effect of unsaturation.

The generalized Richards' equation and Darcy's law governing pressure distribution and water flow in saturated-unsaturated media are simulated with the Galerkin finite-element method subject to appropriate initial and four types of boundary conditions. The hydrological transport equations (a set of PDEs) are derived based on the principle of conservation of mass, and the geochemical equilibrium equations (a set of AEs) are derived based on the mass balance and mass action. The coupled set of PDEs and AEs are simulated with either the conventional finite-element methods or the hybrid Lagrangian-Eulerian finiteelement method with peak capturing scheme subject to appropriate initial and four types of boundary conditions. Hexahedral elements, triangular prism, and tetrahedral elements are used to facilitate the discretization of the region of interest.

Application: Chemical and water diffusion Agency Point of Contact/Reference: Cheng, H. P., and Yeh, G. T. (1998). "Development of a three-dimensional model of subsurface flow, heat transfer, and reactive chemical transport; 3DHYDROGEOCHEM," Journal of Contaminant Hydrology 34, 47-83.

Model Name: Vadose zone leaching, saturated zone mixing, and groundwater flow (VG) model

Description: The vadose zone leaching, saturated zone mixing, and groundwater flow (VG) model was developed as a user-friendly model with a graphic user interface and the capability of simulating a vertical heterogeneous aquifer. A 1-D finite difference scheme was employed for solving the leaching equation in a 
vertically heterogeneous vadose zone. The transport processes, including liquidphase advection, liquid- and vapor-phase dispersion, sorption, and decay of contaminant, were taken into account. The transport processes in all the phases were combined in one equation under the assumption of the instantaneous linear equilibrium partitioning relationships. This not only provided more consistent formation, but also was computationally more efficient since only one differential equation needed to be solved. The mass-balance principle was used for the mixing calculation within the top portion of the aquifer at the bottom of the vadose zone. A 2-D finite difference method was employed for developing a 2-D heterogeneous groundwater flow sub-model. This sub-model provides determination of the contaminant track in the heterogeneous saturated zone, and evaluation of the natural rate of groundwater flow and the risk of contaminant. Soil column tests were performed to test the validity of the model. Three different soil sample sizes of Ottawa quartz sand and $480 \mathrm{ppm}$ saline water as groundwater contamination were used in the validation test. The important input parameters of soil properties in these simulations were effective porosity, water filled porosity, and bulk density. In the field study at Wood River Junction, RI, the developed model demonstrated its useful performance for evaluating a regional aquifer contaminant site by a good match between simulated data and historical data.

Application: Vadose zone leaching, saturated zone mixing, and groundwater flow

Agency Point of Contact/Reference: U.S. EPA

Model Name: Methane Emissions in Rice Ecosystems (MERES)

Description: The Methane Emissions in Rice Ecosystems (MERES) model (Matthews et al. 2000) is used to simulate methane $\left(\mathrm{CH}_{4}\right)$ emissions from rice fields. The MERES-Rice crop simulation modeled was developed by combining existing routines simulating soil organic matter (SOM) decomposition to predict the amount of substrate available for methanogenesis and models developed by Arah and Kirk (2000) to calculate steady-state fluxes and concentrations of $\mathrm{CH}_{4}$ and $\mathrm{O}_{2}$ in flooded soils. Routines were also incorporated to simulate the influence of combined pool of alternative electron acceptors in the soil (i.e., $\mathrm{NO}_{3}, \mathrm{Mn}_{4}+$, $\left.\mathrm{Fe}_{3}+, \mathrm{SO}_{4}\right)$ on $\mathrm{CH}_{4}$ production. Calculations are made defining the 1) rate of decomposition of soil organic material from the previous crop or the addition of organic matter, 2) root exudates, and 3) the decomposition of dead roots from the current crop. A certain fraction of this rate of substrate supply, determined by the concentration of the oxidized form of the alternative electron acceptor pool, is converted to $\mathrm{CO}_{2}$ by bacteria that outcompetes the methanogenic bacteria, thereby suppressing $\mathrm{CH}_{4}$ production. The $\mathrm{CH}_{4}$ dynamics submodel uses this potential methanogenesis rate, along with a description of the root length distribution in the soil profile supplied by the crop model, to calculate the steadystate concentrations and fluxes of $\mathrm{O}_{2}$ and $\mathrm{CH}_{4}$. The reduced form of the alternative electron acceptor pool is allowed to reoxidize when soil pores fill with air if the field is drained. The MERES model was able to explain well the seasonal patterns of $\mathrm{CH}_{4}$ emissions in an experiment involving mid- and endseason drainage and additions of organic material.

The soils model internal to MERES is described by the initial organic matter, nitrogen $(\mathrm{N})$ content, water-holding properties, and texture. The soil depth of interest is $50 \mathrm{~cm}$. To compute diffusion of $\mathrm{CH}_{4}$ and $\mathrm{O}_{2}$ in the soil, data are 
provided to the model in terms of leaching rate, root-mediated influx, and rate of composition of the material, root-mediated efflux, and rate of ebullition. Conrad et al. (1987) suggest that the syntropic microbial process involved in supplying substrate were more sensitive to temperature than methanogenesis. However, available evidence suggests that the effect of temperature on oxidation rate is small (Dunfield et al. 1993).

Application: Vegetation, water, chemical transport

Agency Point of Contact/Reference: Matthews et al. 2000

Model Name: Pumpanen Model

Description: The Pumpanen Model is a soil model of carbon dioxide efflux and concentration that was developed by Pumpanen et al. (2003). The model uses a water budget routine to track water migration and temperature changes to illustrate fluctuations of carbon dioxide. The model simulates soil carbon dioxide concentrations and efflux using hourly values for soil temperatures, volumetric soil water contents, and ambient air carbon dioxide concentrations as input. The calculation proceeds in an order where first the initial values of soil parameters such as the thickness and the total porosity of soil layers and soil parameter values are given. The values for the soil volume metric water content, the temperature, and the ambient air $\mathrm{CO}_{2}$ concentration above the soil surface are read from an input file. The flux rates of $\mathrm{CO}_{2}$ between the soil layers (and from the hums to the air) are computed.

Application: Chemical transport Agency Point of Contact/Reference: Pumpanen, J., Ilvesniemi, H., and Heri, P. (2003). "A process-based model for predicting soil carbon dioxide efflux and concentration," Soil Science Society of America 67, 402-413.

Model Name: Coup Model

Description: The Coup Model was developed to simulate the soil water and heat transfer process for bare soils and vegetation-covered soils. The basic structure of the model is a depth profile of the soil. Processes such as snow-melt, interception of precipitation, and evapotranspiration are examples of important interfaces between soil and atmosphere. Two coupled differential equations for water and heat flow represent the central part of the model. These equations are solved with an explicit numerical method. The basic assumptions behind these equations are:

(i) The law of conservation of mass and energy.

(ii) Darcy's Law (flows occur as a result of gradients in water potential) or Fourier's Law (flows occur as a result of gradients in temperature).

Application: Water and temperature diffusion Agency Point of Contact/Reference: Department of Land and Water Resources Engineering, Sweden

Model Name: SHAW Model

Description: The SHAW Model simulates heat, water, and solute transfer in a one-dimensional profile extending from the top of a plant canopy or the snow, residue, or soil surface to a specified depth within the soil. The system is represented by integrating detailed physics of vegetative cover, snow, residue and soil into one simultaneous solution. The model is sufficiently flexible to represent a broad range of conditions and the system may or may not include a vegetative canopy, snow, or a residue layer. Interrelated heat, water, and solute 
fluxes are computed throughout the system and include the effects of soil freezing and thawing. Daily or hourly predictions include evaporation, transpiration, percolation, soil frost depth, snow depth, runoff, and soil profiles of temperature, water, ice, and solutes.

Unique features of the model include: simultaneous solution of heat, water, and solute fluxes; detailed provisions for soil freezing and thawing; and a sophisticated approach to simulating transpiration and water vapor transfer through a multi-species plant canopy. The model has been used to accurately predict the effects of management, climate, slope, and vegetation on energy and water transfer at the soil-atmosphere interface and temperature and water conditions near the soil surface and within the soil profile.

Application: Vegetation, soil, snow, temperature, water diffusion Agency Point of Contact/Reference: USDA Agricultural Research Service 


\section{Appendix B Vegetation and Water Models}

Model Name: Thermal Vegetation Canopy Model

Description: Optical and Thermal IR canopy model

Application: Modeling the physical temperature of vegetation canopies

Agency Point of Contact/Reference: Smith et al. 1981

Model Name: CE-QUAL-W2

Description: Steady-state model of reservoir water temperatures

Application: Modeling the surface temperature of standing water.

Agency Point of Contact/Reference: Cole and Buchak 1995

Model Name: CUPID

Description: Comprehensive model of plant-environment interaction

Application: CUPID is a comprehensive soil-plant-atmosphere model that uses inputs of leaf physiological characteristics (photosynthesis, stomatal conductance, and respiration), canopy architecture, and soil characteristics (heat and water properties) with boundary conditions at the bottom of the root zone and above the canopy to predict plant-environment interactions of many kinds. Examples include water budgets of irrigated crops, plant-pest-microenvironment interactions, canopy light-use efficiency, water-use efficiency, canopy energy budgets, leaf wetness duration, and remote sensing applications.

Agency Point of Contact/Reference: Norman 1979

Model Name: Hyperspectral Canopy Reflectance Model

Description: Hyperspectral canopy reflectance model based on measured input parameters.

Application: Remote sensing modeling of satellite hyperspectral imagers. Agency Point of Contact/Reference: Ballard and Smith 2002a

Model Name: Enhanced land surface model with discontinuous upper canopy

Description: A radiative transfer model in which vegetation canopies are represented by two layers.

Agency Point of Contact/Reference: Hanan 2001 
Model Name: Leaf transpiration and sap flow model

Description: Detailed simulation of leaf transpiration and sap flow in virtual plants

Application: The use of virtual plants with detailed geometry to calculate the radiative and energy balances of individual leaves and the use of topology of the virtual plants to calculate sap flows and resulting water potentials.

Agency Point of Contact/Reference: Dauzat et al. 2001

Model Name: TreeTherm

Description: 3-D tree thermal response model for energy budget and scene simulation studies

Application: Thermal signatures of trees for scene simulation studies. Agency Point of Contact/Reference: Hummel et al. 1991

Model Name: Vegetation Canopy Terrain Model (VCTM) or VEGIE

Description: Inclusion of a simple vegetation canopy layer in a thermal model of terrain surface elements

Application: Terrain thermal studies.

Agency Point of Contact/Reference: Balick et al. 1981b

Model Name: SAIL canopy reflectance model

Description: The scattering and extinction coefficients of the SAIL canopy reflectance model are derived for the case of a fixed arbitrary leaf inclination angle and a random leaf azimuth distribution. The SAIL model includes the uniform model of G. H. Suits as a special case. Main characteristics are that canopy variables such as leaf area index and the leaf inclination distribution function are used as input parameters and that SAIL provides more realistic angular profiles of the directional reflectance as a function of the view angle or the solar zenith angle.

Application: Modeling spectral signatures of a vegetation canopy. Agency Point of Contact/Reference: Verhoef 1984

Model Name: Leaf Temperature Model

Description: The leaf temperature model derived from the Penman-Monteith model simulated the 3-D distribution of foliage elements and the effect of solar loading based in the incidence angle.

Agency Point of Contact/Reference: Smith and Ballard 1999, Smith and Ballard 2001.

Model Name: Water transport and storage in tree sapwood model Description: A single tree water flux model that combines a stomatal conductance model with the concept of fluid dynamics to describe water transportation and storage in sapwood.

Application: Soil-plant-atmosphere studies.

Agency Point of Contact/Reference: Kumagai 2001 


\section{Appendix C Sensor Models}

\section{Introduction}

This appendix provides a list of sensor models that can be used for detection of buried or surface mines. The geophysical, environmental, and atmospheric models alter the signature landscape and the sensor model emulates the system that discriminates the mine from landscape signatures. A signal generated from the ground in many instances will pass through the soil, vegetation, and atmosphere in which it may be refracted, absorbed, or scattered; subsequently it may be refracted, reflected, diffracted, or polarized by the sensor model. The sensor models define the detection method by employing different algorithms, filtering strategies, fusing techniques, and/or adapting different methods refining temporal and spatial changes in the environment. Sensor models are designed around spectral response, spatial sampling, optomechanical projection, temporal changes, noise reduction, and calibration techniques. There are many sensor models for this task and only a partial sample is specifically represented here. However, the sample is large enough to evaluate the status of the general modeling capabilities that exist specifically for detection of mines. Many sensor manufacturers generate detailed sensor descriptions of specific sensors during design and calibration, which are incorporated into propriety in-house sensor models. As a result, many sensor models are not generally available (Schott et al. 2001).

\section{Background}

Sensor technologies described by Ackenhusen et al. (2001) are summarized in Table C1. Sensor models directly support technologies whose cost and complexity are high and maturity is far away. It must be noted, however, that thermal IR numerical modeling in this area is entirely focused on simulating temperature anomalies and detection while the newest sensors are being designed to detect spectral anomalies in the thermal infrared part of the spectrum.

It is also important to include sensor models and detection algorithms in a comprehensive modeling system for thermal IR mine detection. The sensor modulates the signal predicted by the environmental models. Signal-to-noise 
ratio is one useful measure, but the effects of the optical system on the signal are complex, especially for imaging systems.

\begin{tabular}{||l|l|l||}
\hline \hline \multicolumn{2}{||l||}{ Table C1 } \\
Sensor Technologies (Ackenhusen et al. 2001) \\
\hline \hline Sensor Technology & Maturity & Cost and Complexity \\
\hline \hline Probe & Complete & Low \\
\hline Visible broadband & Complete & Low \\
\hline Infrared broadband passive & Near & Medium \\
\hline Infrared broadband active & Near & Medium \\
\hline Polarimetric & Near & Medium \\
\hline Spectral & Near & Medium \\
\hline Streak-tube imaging LIDAR (STIL) & Near & Current \\
\hline Electromagnetic induction & Near & Current \\
\hline Penetrating radiation & Far & Medium \\
\hline Passive mm-wave & Far & High \\
\hline mm-wave radar & Near & High \\
\hline Ground-penetrating radar (GPR) & Near & Medium \\
\hline Ultra-wideband radar & Far & High \\
\hline Active seismic & Mid & Medium \\
\hline Active acoustic & Mid & Medium \\
\hline Magnetic field sensing & Near & Medium \\
\hline Metal detection & Available & Low \\
\hline Neutron activation analysis & Near & High \\
\hline \hline
\end{tabular}

Table C2 is a list of current sensor models. Sensor models ranged from those mimicking human eyesight to those that model other spectrums and anomalies to define a mine. Target models such as a model emulating the signals emitted from a mine and a sensor model are overlapping. Some models included in Table C2 are scene simulation systems, which include characteristics of several different sensor models.

The most advanced sensor models include spatial, spectral, and temporal variation in the radiance field induced both by the scene, the view geometry, and the sensor opto-mechanical process. NVTherm, DIRSIG, and CameoSim appear to have many of these features. CameoSim and DIRSIG are scene simulation models and potentially more useful in modeling the signature of a minefield. 


\begin{tabular}{||l|l|l||}
\hline \hline \multicolumn{2}{||l||}{\begin{tabular}{l||} 
Table C2 \\
Summary of Sensor Models
\end{tabular}} \\
\hline \hline Sensor Model & Laboratory & Comments \\
\hline \hline M2MTI & MITRE & Radar detection/monitoring \\
\hline NVTherm & NVESD & Thermal detection \\
\hline Neoclassical Search Model & IDA & Human vision sensor \\
\hline ORACLE & British Aerospace PLC & Visible/thermal sensor \\
\hline GTRI & Georgia Tech & Clutter filter/sensor \\
\hline Acquire & CECOM & Line of sight sensor \\
\hline TARGAC & ARL & Data fusion/detection \\
\hline RADAR & ARL & Radar model \\
\hline AgentStorm & Carnegie Mellon University & Team-aware demining agent \\
\hline MM-MNF & Johns Hopkins University & Detection with multispectral imagery \\
\hline TopAttack & USACE & Thermal detection sensor \\
\hline IRMA/ENVIRO & USAFAL & Thermal detection sensor \\
\hline SIRIM & IRIA & Predicts thermal target signatures \\
\hline JDL Fusion Model & JDL & GPR, EMl, and MAG combined \\
\hline ModTran & USAF & Spectral image \\
\hline DIRSIG & DCS Corp & Spectral and thermal image \\
\hline FASCODE & USAF & Spectral image \\
\hline CameoSim & UK (DSTL/In-sys) & Spectral and thermal image \\
\hline \hline
\end{tabular}




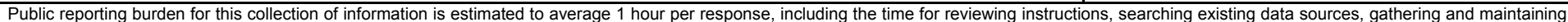

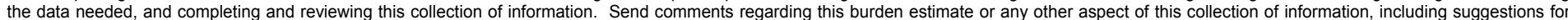

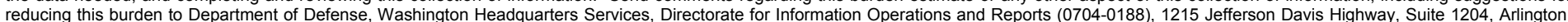

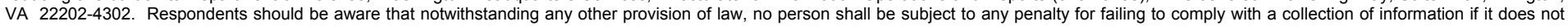
display a currently valid OMB control number. PLEASE DO NOT RETURN YOUR FORM TO THE ABOVE ADDRESS.

\begin{tabular}{l|c}
$\begin{array}{l}\text { 1. REPORT DATE (DD-MM-YYYY) } \\
\text { March } 2004\end{array}$ & $\begin{array}{c}\text { 2. REPORT TYPE } \\
\text { Final report }\end{array}$ \\
\hline
\end{tabular}

4. TITLE AND SUBTITLE

Phenomenological Models for Landscape Signatures: Review and

Recommendations

3. DATES COVERED (From - To)

5a. CONTRACT NUMBER

5b. GRANT NUMBER

5c. PROGRAM ELEMENT NUMBER

6. AUTHOR(S)

5d. PROJECT NUMBER

Jerrell R. Ballard, Jr., George L. Mason, James A. Smith, Lee K. Balick

5e. TASK NUMBER

5f. WORK UNIT NUMBER

7. PERFORMING ORGANIZATION NAME(S) AND ADDRESS(ES)

8. PERFORMING ORGANIZATION REPORT NUMBER

Environmental Laboratory, Geotechnical and Structures Laboratory, U.S. Army Engineer Research and Development Center, 3909 Halls Ferry Road, Vicksburg, MS 3918-6199; Laboratory for Terrestrial Physics, NASA Goddard Space Flight Center, Greenbelt, MD 20771; Space and Remote Sensing Sciences Group (NIS-2), Los Alamos National Laboratory, Los Alamos, NM 87545

9. SPONSORING / MONITORING AGENCY NAME(S) AND ADDRESS(ES)

ERDC TR-04-2

U.S. Army Study Program Management Office - G8, 1725 Jefferson Davis Highway,

Crystal Square 2, Suite 201A, Arlington, VA 22202

10. SPONSOR/MONITOR'S ACRONYM(S)

11. SPONSOR/MONITOR'S REPORT NUMBER(S)

\section{DISTRIBUTION / AVAILABILITY STATEMENT}

Approved for public release; distribution is unlimited

\section{SUPPLEMENTARY NOTES}

\section{ABSTRACT}

This report reviews, evaluates, and recommends atmospheric, vegetation and water, and soil models that use physics to aid in understanding the impact that the natural environment has on the sensors that are commonly applied to the mine detection problem (either surface or buried). The report lists important predictive high-resolution atmospheric, vegetation and water, and soil models. Priority models are evaluated to indicate their strengths and weaknesses. The report recommends areas needing further development to fill the gaps in predicting the effects of critical environmental factors on developing mine detection sensors.

\section{SUBJECT TERMS}

Atmospheric models

Background models

16. SECURITY CLASSIFICATION OF:

\begin{tabular}{|l|l|}
\hline a. REPORT & b. ABSTRACT \\
UNCLASSIFIED & UNCLASSIFIED \\
\hline
\end{tabular}

Geophysical models

Sensor models

Signature models

c. THIS PAGE

UNCLASSIFIED
Soil models

Surface water models

Vegetation models

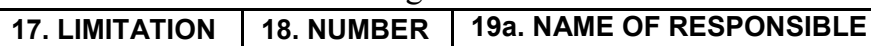
OF ABSTRACT

\section{OF PAGES}

52
PERSON

\section{9b. TELEPHONE NUMBER (include} area code) 